\title{
Calcium-dependent protein kinases from Arabidopsis show substrate specificity differences in an analysis of 103 substrates
}

\section{Amy Curran ${ }^{1+}$, Ing-Feng Chang ${ }^{1,2+}$, Chia-Lun Chang ${ }^{2}$, Shilpi Garg' ${ }^{1}$, Rodriguez Milla Miguel ${ }^{1,3}$, Yoshimi D. Barron', Ying Li', Shawn Romanowsky ${ }^{1}$, John C. Cushman', Michael Gribskov ${ }^{4}$, Alice C. Harmon ${ }^{5}$ and Jeffrey F. Harper ${ }^{1 *}$}

1 Department of Biochemistry and Molecular Biology, University of Nevada, Reno, NV, USA

2 Institute of Plant Biology, National Taiwan University, Taipei, Taiwan

${ }^{3}$ Departamento de Biología de Plantas, Centro de Investigaciones Biológicas, Madrid, Spain

${ }_{4}^{4}$ Department of Biological Sciences, Purdue University, West Lafayette, IN, USA

${ }^{5}$ Department of Biology, University of Florida, Gainesville, FL, USA

Edited by:

Rodrigo Gutierrez, Pontificia

Universidad Catolica de Chile, Chile

Reviewed by:

Sorina Claudia Popescu, Boyce

Thompson Institute for Plant Research,

USA

lan Wallace, University of California,

USA

*Correspondence:

Jeffrey F. Harper, Biochemistry

Department, University of Nevada,

Reno MS330, Howard Building, Reno,

NV 89557, USA.

e-mail: jfharper@unr.edu

${ }^{+}$Amy Curran and Ing-Feng Chang have contributed equally to this work.
The identification of substrates represents a critical challenge for understanding any protein kinasebased signal transduction pathway. In Arabidopsis, there are more than 1000 different protein kinases, 34 of which belong to a family of $\mathrm{Ca}^{2+}$-dependent protein kinases (CPKs). While CPKs are implicated in regulating diverse aspects of plant biology, from ion transport to transcription, relatively little is known about isoform-specific differences in substrate specificity, or the number of phosphorylation targets. Here, in vitro kinase assays were used to compare phosphorylation targets of four CPKs from Arabidopsis (CPK1, 10, 16, and 34). Significant differences in substrate specificity for each kinase were revealed by assays using 103 different substrates. For example CPK16 phosphorylated Serine 109 in a peptide from the stress-regulated protein, Di19-2 with $K_{M}$ $\sim 70 \mu \mathrm{M}$, but this site was not phosphorylated significantly by CPKs 1, 10, or 34 . In contrast, CPKs 1, 10, and 34 phosphorylated 93 other peptide substrates not recognized by CPK16. Examples of substrate specificity differences among all four CPKs were verified by kinetic analyses. To test the correlation between in vivo phosphorylation events and in vitro kinase activities, assays were performed with 274 synthetic peptides that contained phosphorylation sites previously mapped in proteins isolated from plants (in vivo-mapped sites). Of these, 74 (27\%) were found to be phosphorylated by at least one of the four CPKs tested. This $27 \%$ success rate validates a robust strategy for linking the activities of specific kinases, such as CPKs, to the thousands of in planta phosphorylation sites that are being uncovered by emerging technologies.

Keywords: calcium-dependent protein kinase, phosphorylation, substrate specificity, phospho-proteomics

\section{INTRODUCTION}

$\mathrm{Ca}^{2+}$ is an important second messenger in plant cells, and has been linked to the perception of and response to biotic and abiotic stimuli, as well as regulation of many aspects of growth and development (Lecourieux et al., 2006; Ma and Berkowitz, 2007; Kosuta et al., 2008; Song et al., 2008; Bertorello and Zhu, 2009; Cardenas, 2009; Chehab et al., 2009; Kim et al., 2009; Luan et al., 2009; Mazars et al., 2009; McAinsh and Pittman, 2009; Dodd et al., 2010; Hey et al., 2010). In Arabidopsis, $\mathrm{Ca}^{2+}$ signals are potentially decoded by 64 different protein kinases belonging to the CPK/SnRK superfamily $\left(\mathrm{Ca}^{2+}\right.$-dependent protein kinases/sucrose non-fermenting related kinases; Hrabak et al., 2003; Harper et al., 2004). Of these, 34 are CPKs and 8 are CRKs (CPK-related kinases). CPKs in flowering plants can be further divided into 12 distinct subfamilies that show conservation between rice and Arabidopsis. The CPKs have a unique structure in which a calmodulin-like regulatory domain is present at the C-terminal end of the kinase (Harper et al., 1991; Harper

Abbreviations: CaM, calmodulin; CPK, calcium-dependent protein kinase; ps, plasmid stock number; ss, seed stock number. and Harmon, 2005; Wernimont et al., 2010). CRKs differ in having a degenerate calmodulin-like domain containing substitutions expected to disrupt the $\mathrm{Ca}^{2+}$ binding EF hands (Harper et al., 2004). Nevertheless, at least some CRKs can be activated by $\mathrm{Ca}^{2+}$ through a bimolecular interaction with calmodulin (Jeong et al., 2007).

Although CPKs have not been found in animals, they appear to be widespread in flowering plants, algae, and certain apicomplexan protists (Harper and Harmon, 2005). In plants, CPKs and related kinases have been implicated in multiple aspects of growth and development (Klimecka and Muszynska, 2007), for example, pollen tube growth (Yoon et al., 2006; Myers et al., 2009); root development (Ivashuta et al., 2005); defense responses (Ludwig et al., 2005; Freymark et al., 2007; Arimura and Maffei, 2010; Boudsocq et al., 2010; Coca and San Segundo, 2010; Kanchiswamy et al., 2010); regulation of reactive oxygen species (ROS) production (Kobayashi et al., 2007); symbiotic interactions (Gargantini et al., 2006; Gleason et al., 2006; Oldroyd and Downie, 2006; Tirichine et al., 2006; Marsh et al., 2007; Tsai et al., 2007; Yano et al., 2008; Hayashi et al., 2010); guard cell turgor (Mori et al., 2006; Geiger et al., 2010; Xu et al., 2010; Zou et al., 2010; Munemasa et al., 2011); osmotic, drought, and salt stress 
(Ma and Wu, 2007; Zhu et al., 2007; Mehlmer et al., 2010; Witte et al., 2010; Asano et al., 2011; Franz et al., 2011); and regulation through hormones such as ABA (Choi et al., 2005) and GA (McCubbin et al., 2004; Yuan et al., 2007; Ishida et al., 2008). In apicomplexans that cause malaria and toxoplasmosis, CPKs are essential for development, making them attractive drug targets (Kato et al., 2008; Billker et al., 2009; Dvorin et al., 2010; Lourido et al., 2010).

Despite being implicated in so many diverse aspects of plant and protozoan biology, relatively little is known about the downstream substrates regulated by CPKs. CPKs are expected to be multifunctional, with many target substrates. This speculation is supported by analogy to CaM-dependent kinases in animals (CaMKs), as well as an expanding list of candidate substrates tested by in vitro kinase reactions (e.g., Harper et al., 2004; Klimecka and Muszynska, 2007; Kanchiswamy et al., 2010).

While most candidate substrates for CPKs have been identified through in vitro kinase reactions, there are several for which there is evidence of in vivo phosphorylation or a kinase-substrate interaction, including the following. A tobacco CDPK1 has been implicated in regulating the phospho-dependent binding between a 14-3-3 protein and a transcription factor (RSG) involved in mediating GA signaling (Ishida et al., 2008; Ito et al., 2010). Isoforms AtCPK21 and 23 have been implicated in binding and activating a guard cell anion channel SLAC1 (Geiger et al., 2010). For AtCPK32, evidence supports an interaction with an $\mathrm{ABA}$-induced transcription factor (ABF4) that can alter ABA-triggered responses (Choi et al., 2005). A soybean CPK has been linked to the regulation of a serine acetyltransferase in response to oxidative stress (Liu et al., 2006). Nitrate reductase (NR) activity can be regulated by CPK phosphorylation, which promotes a phospho-dependent binding interaction with 14-3-3 proteins (Bachmann et al., 1996; Douglas et al., 1997, 1998; Lambeck et al., 2010).

Multiple strategies have been used to help identify substrates for CPKs and other kinases in plants (Peck, 2006; de la Fuente van Bentem et al., 2008; Kersten et al., 2009; Uno et al., 2009; Huang et al., 2010; Mehlmer et al., 2010). While a "one protein at a time" strategy is still relevant, proteome-wide surveys employing mass spectrometry have rapidly expanded the list of mapped phosphorylation sites in plant proteomes since 2003 (Nuhse et al., 2003). An important aspect of these surveys is their potential to identify phosphorylation sites occurring in vivo (in vivo-mapped sites). However, correlating these data with the specific kinases responsible for each phosphorylation event remains a challenge. To this end, custom-designed peptide libraries provide a strategy to rapidly test large numbers of in vivo-mapped phosphorylation sites for their potential to be phosphorylated by a specific kinase.

Here we present results from three complementary strategies used to help identify CPK substrates. The first approach was a survey of candidate proteins using in vitro kinase reactions, followed by phosphorylation site mapping using mass spectrometry. The second approach was to test 274 in vivo-mapped phosphorylation sites (Peck, 2006; de la Fuente van Bentem et al., 2008; Kersten et al., 2009; Uno et al., 2009; Huang et al., 2010; Mehlmer et al., 2010) for their potential to be phosphorylated in vitro by a particular $\mathrm{CPK}$. The third approach was to test sites that were predicted based on consensus phosphorylation site information. For example, 206 of the predicted sites tested here were derived from proteins with evidence for a 14-3-3 interaction (Chang et al., 2009). Potential 14-3-3 binding sites were considered logical candidates for CPK substrates because a consensus site proposed for CPK phosphorylation overlaps with many phospho-sites implicated in 14-3-3 binding interactions (Johnson et al., 2010). Because most 14-3-3 interactions are thought to be mediated by phosphorylation, this focus was postulated to enrich for potential CPK sites of biological relevance.

Using peptides derived from both in vivo mapping and bioinformatic prediction strategies, we identified 89 new peptide substrates that were recognized by at least one of four CPKs tested (isoforms $1,10,16$, and 34). These new peptide substrates, in addition to 13 reference peptides, revealed significant differences in substrate specificity for each of the four CPKs. Isoform CPK16 recognized the fewest substrates (nine), whereas CPK34 recognized the most (97 total, 31 of which were isoform-specific). This observed diversity of substrate specificity helps explain the origin of more than seven different CPK consensus sites that have been proposed from different studies based on different isoforms (Harper et al., 2004). This survey also supports a model for CPK signaling networks in which substrate specificity contributes to the isoform-specific functions of different CPKs.

\section{RESULTS}

\section{DI19-2 IS A G00D SUBSTRATE FOR CPK16, BUT NOT CPK1, 10, AND 34}

To search for potential CPK16 substrates, we initiated a survey of protein and peptide substrates using in vitro kinase assays. One group of proteins tested included members of a family of droughtinduced proteins (Di19s; Milla et al., 2006; Rodriguez Milla et al., 2006; data not shown). Some Di19s had previously been found to interact with CPKs in a yeast two-hybrid screen (Rodriguez Milla et al., 2006). Isoform Di19-2 was chosen for further analysis because it was strongly phosphorylated by CPK16 (Figure 1). In contrast, assays of Di19-2 with three other CPKs (1, 10, and 34) showed more than 10-fold lower levels of phospho-labeling.

All four CPKs were further tested in parallel reactions with a fusion protein containing a known CPK phosphorylation site found in NR. In this case, CPK16 showed weaker substrate labeling compared with the other three CPKs. In contrast, the phosphorylation of substrate Di19-2 site S109 was more than 10-fold stronger for CPK16 than for the other three kinases (in Figure 1, compare lane NR with Di19-2 site S109 wt; discussed in more detail below). This inverse relationship of relative labeling efficiencies indicated that CPK16 had a distinct substrate preference compared to CPKs 1, 10 , and 34 .

To identify CPK16 phosphorylation sites in Di19-2, a fusion protein was phosphorylated, digested by trypsin or Glu-C, and analyzed by mass spectrometry. Residue S109 was identified as a phosphorylation site (data not shown). This site was subsequently confirmed using a fusion protein substrate that displayed the region from D99 to Y115 (described below). CPK16 also phosphorylated additional sites in Di19-2, as indicated by the observation that phosphorylation was still detected in a full-length Di19-2 fusion protein in which the S109 site was substituted with an alanine (S109A, data not shown).

To conduct a more detailed analysis on the $\mathrm{S} 109$ site, a fusion protein (G-S109-ST2) was engineered that displayed a fragment from D99 to Y115 (DVLKS ${ }_{103}$ EQKEMS $_{109}$ YREDPY), flanked 


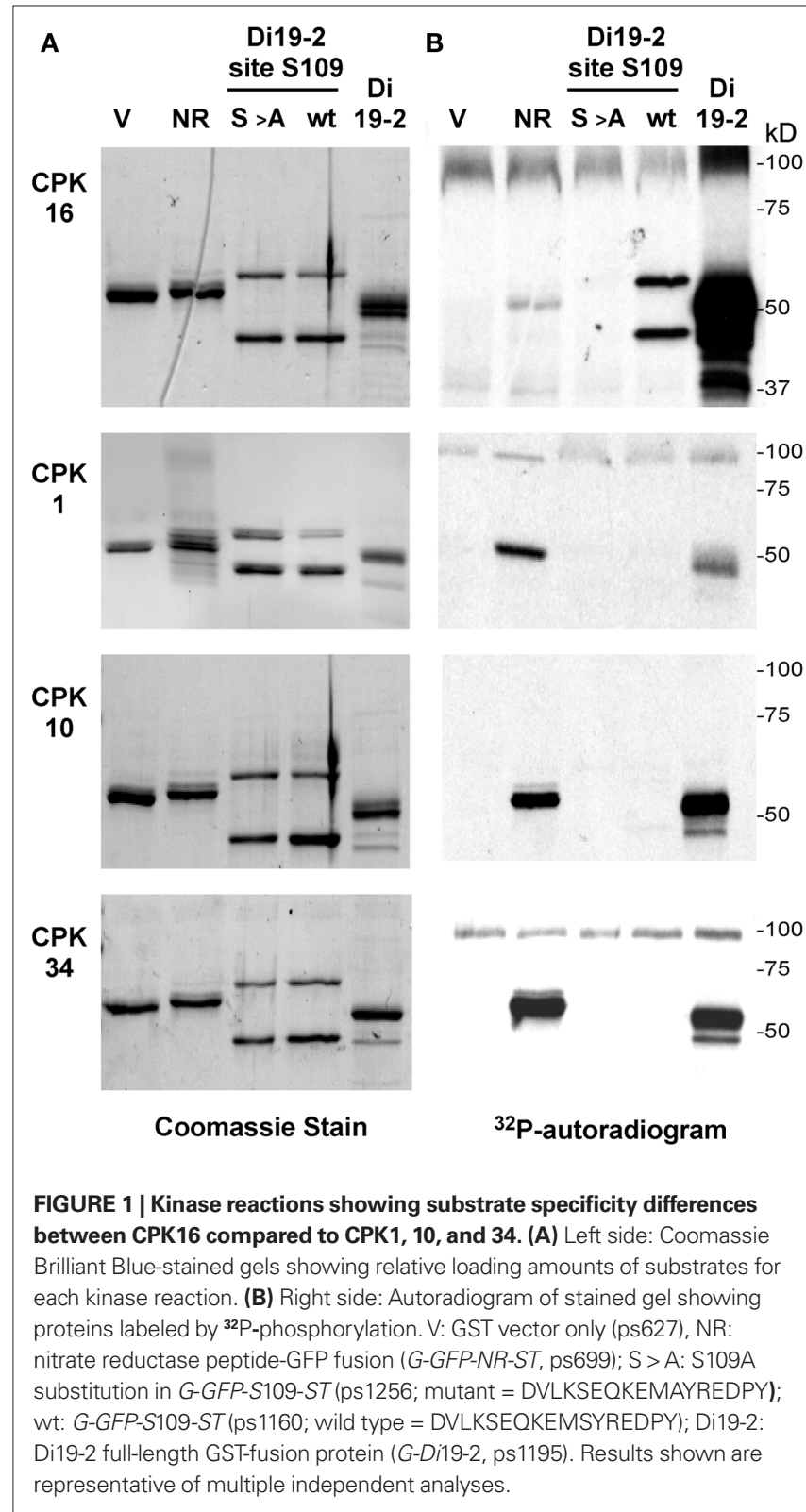

by two purification tags - an upstream GST-GFP (Glutathione S-Transferase-Green Fluorescence Protein), and a downstream Strep-2 tag (Figure 2). For comparison, a parallel fusion protein was created with an established CPK phosphorylation site from NR (Figure 2, NR sequence).

As expected for a CPK substrate, phosphorylation of the G-S109-ST2 fusion protein was stimulated by $\mathrm{Ca}^{2+}$ (Figure 3). This fusion protein substrate was consistently purified as mixture of two proteins (approximately 60 and $30 \mathrm{kD}$; Figure 3 ). The larger protein migrated at the predicted size for the engineered GST-GFPpeptide fusion. The smaller fragment was assumed to be a product of proteolysis. As shown below, both fragments were found to have a single CPK16 phosphorylation site.

To confirm that CPK16 phosphorylates S109 (and not nearby S103), the fusion protein was re-engineered with two separate substitutions and tested for phosphorylation by CPK16. First, a substitution

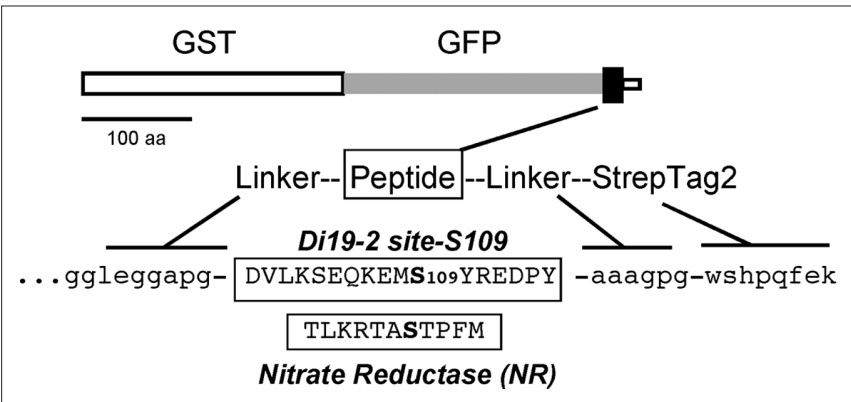

FIGURE 2 | Diagram of the fusion protein system used for analysis of CPK phosphorylation sites from Di19-2 (G-S109-ST, ps1160) and nitrate reductase (ps699). In some experiments, a similar fusion system was used in which the GFP was replaced by an RFP (G-RFP-NR-ST, ps630).

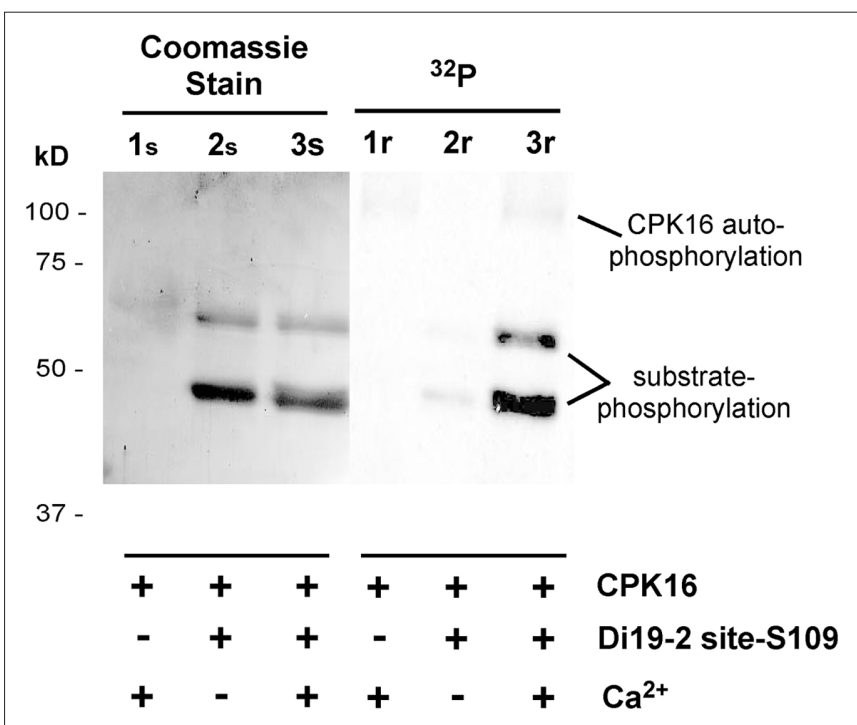

FIGURE 3 | Kinase reactions showing $\mathrm{Ca}^{2+}$-dependent phosphorylation of a Di19-site-S109 fusion protein (G-GFP-S109-ST) by CPK16. Three kinase reactions are shown on the left side after separation on an SDS-12\% polyacrylamide gel and staining with Coomassie Brilliant Blue (1s,2s, 3s). The same gel is shown to the right as an autoradiogram to show the ${ }^{32} \mathrm{P}$-labeling of phosphorylated proteins (1r, 2r, 3r). Kinase reactions were conducted as described in Section "Materials and Methods," plus (+) or minus (-) $\mathrm{Ca}^{2+}$, with $1 \mu \mathrm{g}$ of fusion protein substrate, $0.01 \mu \mathrm{g}$ of kinase, in a $10-\mu \mathrm{L}$ reaction. After a 10-min incubation, the entire reaction was subjected to SDS-PAGE. In control reactions, CPK16 did not phosphorylate the GST-GFP portion of the Di19-2-site-S109 fusion protein (e.g., see Figure 1). Note that the purified G-GFP-S109-ST fusion protein runs as two bands with apparent molecular weights of 48 and $60 \mathrm{kD}$. Results shown are representative of multiple independent analyses.

of S109 to A (S > A) was shown to eliminate any detectable labeling, consistent with S109 serving as the target phosphorylation site (Figure 4, and see Figure 1 to compare lane S > A to wt). Second, a substitution of S103 to A (a potential site upstream of S109) failed to result in any decrease in phosphorylation, confirming that S103 was not needed for substrate labeling. These results confirmed that fusion protein G-S109-ST2 has a single CPK16 phosphorylation site at S109.

To further define the residues surrounding S109 that were important for CPK16 phosphorylation, 26 additional site-specific substitutions were introduced and tested for their effect on 


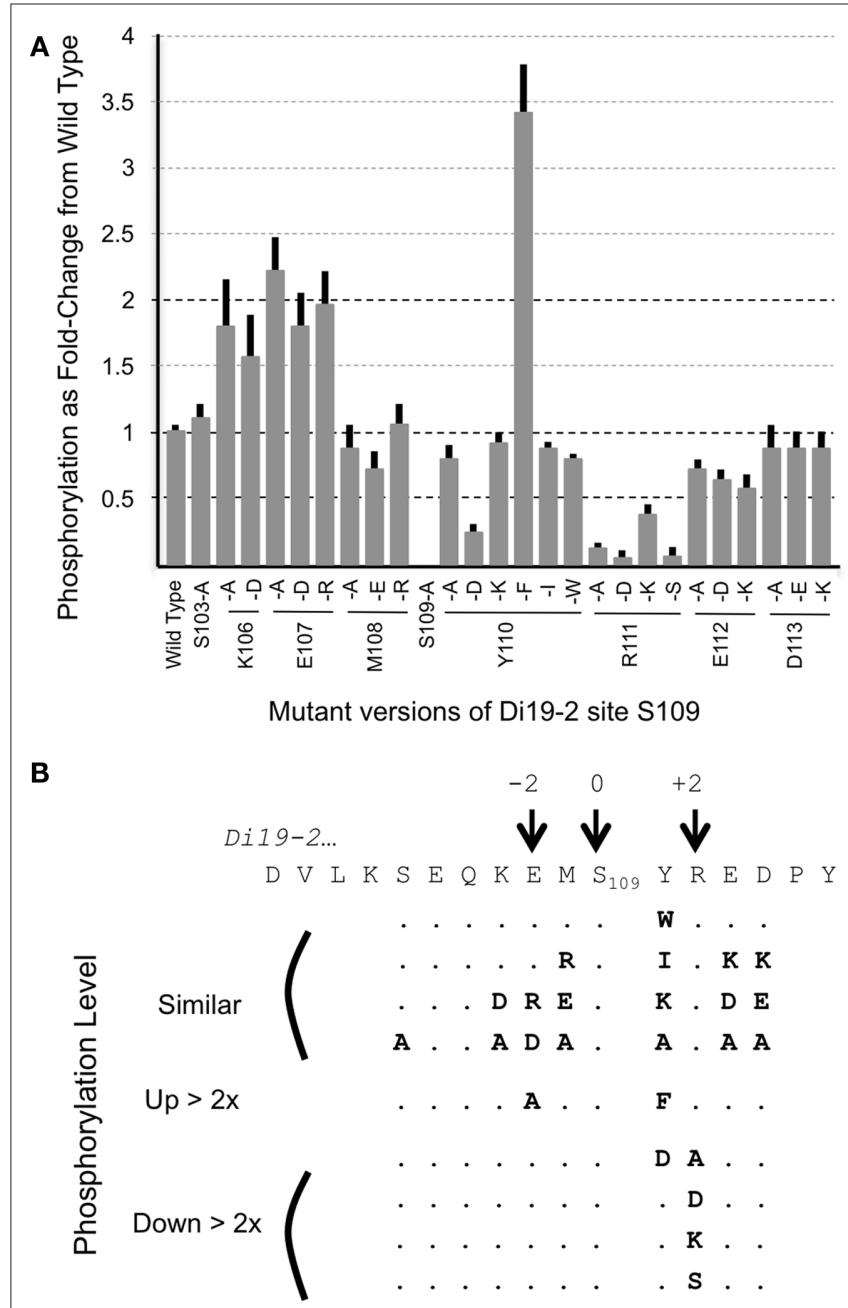

FIGURE 4 | Kinase reactions with CPK16 comparing relative phospholabeling of Di19-2-site-S109 and variants. (A) For each amino acid substitution, the fold change in phosphorylation is shown in comparison to phosphorylation levels for the wild type version of the S109 site encoded in G-GFP-S109-ST. All substitutions were engineered by site-specific mutagenesis of the same parental clone, G-GFP-S109-ST. All reactions, SDS-PAGE gels, and autoradiograms were performed as described in Figure 2 and in Section "Materials and Methods." The percentage incorporation of ${ }^{32} \mathrm{P}$ was determined by analysis of autoradiograms and was normalized to the amount of Coomassie Brilliant Blue-stained protein for each substrate. Results shown are the average of at least four independent analyses for each variant. Error bars show SD. (B) A summary of changes in phosphorylation as a result of substitutions. Peptides with similar phosphorylation potentials are shown first (i.e., changes less than twofold compared to wild type), followed by those that were higher or lower by more than twofold.

phosphorylation (Figure 4). Two positions appeared very sensitive to changes. At position +1 (Y110), a more than two-fold decrease in phosphorylation was observed by the substitution of a Y to D (acidic), but not a Y to $\mathrm{K}$ (basic). This indicates that a negative charge in this location is detrimental. However, a Y to F substitution showed a greater than three-fold improvement in phosphorylation. Because alternative hydrophobic substitutions of $\mathrm{W}$ or I failed to show similar improvements, the $\mathrm{Y}$ to $\mathrm{F}$ substitutions identifies a specific hydrophobic residue that is highly preferred at this location. At position +2 (R111; Figure 4), a more than two-fold decrease in phosphorylation was observed with all four substitutions. This included a conservative substitution of $\mathrm{R}$ to $\mathrm{K}$. In total, the analysis of these 26 substitutions supports a classification of site S109 as a specific variation of a CPK "simple-2" consensus site (Harper and Harmon, 2005), which was defined as (S/T) $\times($ Basic). The variation here can be described as (S/T; F preferred, D detrimental; $\mathrm{R}$ preferred over $\mathrm{K})$.

The G-S109-ST2 fusion protein was further tested for phosphorylation by three other CPKs (isoforms 1, 10, and 34; Figure 1, lane Di19-2 site S109 wt). All three failed to provide significant phosphorylation. In side-by-side controls, all three CPKs were confirmed to be as active as CPK16, as indicated by their relatively stronger phosphorylation of a fusion protein harboring a site from NR (see lane NR in Figure 1). The failure of CPK1, 10, and 34 to phosphorylate $\mathrm{S} 109$ is consistent with the original observation that the fulllength Di19-2 was a poor substrate for these three CPK isoforms.

The $K_{\mathrm{M}}$ for the phosphorylation of S109 by CPK16 was determined to be approximately $70 \mu \mathrm{M}$, when assayed in the context of the G-S109-ST2 fusion shown in Figure 2. Surprisingly however, no significant phosphorylation was obtained using a synthetic 15-amino acid peptide containing the S109 site at the center of the peptide. It is not clear if the synthetic peptide failed because of issues with secondary structure, solubility, or the inclusion of a norleucine (NorLeu) substitution at residue M108 (NorLeu was used in synthetic peptides to replace methionines with a nonoxidizable side chain).

\section{PEPTIDE SUBSTRATE SURVEY}

To conduct a more extensive survey for potential CPK substrates, we used four CPKs and compared their relative ability to phosphorylate 713 peptides, of which 179 represented experimental variations from the core list of 534 peptides (Table S1 in Supplementary Material). This library of synthetic peptides was generated based on five criteria: (1) A subset of 274 peptides were based on in vivo phosphorylation sites mapped in proteins isolated from plant extracts (Nuhse et al., 2003, 2004, 2007; Peck, 2006; Benschop et al., 2007; and Harper, unpublished); (2) 206 peptides were based on predicted 14-3-3 phospho-dependent binding sites in proteins for which evidence had previously been obtained for an in vivo interaction with a 14-3-3 (Chang et al., 2009); (3) 14 peptides were based on mapped sites from in vitro phosphorylation reactions with CPKs; (4) 15 peptides were designed based on bioinformatic predictions of potential CPK consensus phosphorylation sites showing strong conservation between rice and Arabidopsis (Harper, unpublished); and (5) the remainder were reference peptides corresponding to phosphorylation sites established for a variety of plant and animal kinases.

The relative phospho-labeling of peptides was compared for each CPK using a scintillation proximity assay (SPA). Of the 534 peptides tested, 102 ("hits") were found to show significant labeling by at least one of the four CPKs tested (Table 1). Of these, 13 were reference peptides, 74 peptides contained phosphorylation sites with evidence for in vivo phosphorylation, and the remaining 15 were predicted sites.

Note that the SPA assays were used here as a survey tool. As it was not practical to conduct the SPA assays under MichaelisMenten conditions, these assays do not represent a rigorous test of 
Table 1 | One hundred two peptides phosphorylated by at least one CPK in this study.

\begin{tabular}{|c|c|c|c|c|c|c|c|}
\hline Peptide & Peptide sequence & AGI\# & CPK1 & CPK10 & CPK16 & СРK34 & Description \\
\hline \multicolumn{8}{|c|}{ REFERENCE PEPTIDES } \\
\hline ach-393 & PLARTLSVAGLPGKK & $\mathrm{n} / \mathrm{a}$ & 6 & 14 & - & 29 & Syntide-2 (PMID-3028265) \\
\hline ach-375 & PIKLDKMㅁSFTM`DH & $\mathrm{n} / \mathrm{a}$ & 7 & - & - & 24 & GmSAT site S367 (PMID-16854983) \\
\hline ach-376 & PIKLDKMPSFTMDH & $\mathrm{n} / \mathrm{a}$ & 5 & - & - & - & GmSAT site S367 (PMID-16854983) \\
\hline ach-407 & KRREILSRRPSYR & $\mathrm{n} / \mathrm{a}$ & 5 & 5 & - & 19 & Crebtide (PMID-7798217) \\
\hline ach-388 & RMRRGVS*CHGR & $\mathrm{n} / \mathrm{a}$ & 4 & 8 & - & 19 & SPS, Suc P Syn, site S424 (PMID-9232876) \\
\hline ach-402 & KKKVSRSGLYRSPSMPENL & $\mathrm{n} / \mathrm{a}$ & - & - & - & 13 & CHK1/2 (PMID-9278511) \\
\hline jfh-225 & GAPTLKRTASTPFMA & $\mathrm{n} / \mathrm{a}$ & 7 & 5 & - & 13 & Nitrate Reductase (based on PMID-8721752) \\
\hline ach-405 & AKRPQRATSNVFS & $\mathrm{n} / \mathrm{a}$ & - & - & - & 13 & MLCK-Sk (PMID-2873140) \\
\hline jfh-752 $2^{\text {bh }}$ & LRELTKSA(S)*FLRAVS & AT5G37810 & 28 & 7 & - & 35 & Aquaporin NIP4.1, pollen paralog of jfh-541 \\
\hline jfh-541 & LREITKSG[S] ${ }^{*}$ FLKTVR & AT4G19030 & 8 & - & - & 18 & Aquaporin NIP1.1, compare to jfh-752 \\
\hline jfh-444 & LAKIKKTQ[S] ${ }^{*}$ QIFKYA & AT1G53390 & 9 & - & - & 32 & ABC transporter \\
\hline jfh-738 h & QPLLQRSL(S)*SPSPRA & АT3G11690 & 23 & 27 & - & 31 & ABC transporter, pollen paralog of jfh- 529 \\
\hline jfh-529e & SPITQRSI[S]IESPRO & АT3G62700 & - & - & - & 12 & ABC transporter MRP10, compare to jfh-738 \\
\hline jfh-515a & VKIISRIF[S]QRSFRR & АT3G27390 & 20 & 24 & 10 & 31 & Expressed protein \\
\hline jfh-729 & RIKLLKFG(S)PS*ARLK & AT5G05350 & 11 & 9 & - & 31 & SAG20-related, pollen paralog of jfh-504 \\
\hline jfh-504 & RFQLLKFG[S]*PSAKFK & AT3G10980 & 15 & 7 & - & 26 & SAG20, Senescence-associated, compare to jfh-729 \\
\hline jfh-590 & NRTLTRNR[S]*LVDVQR & AT5G58350 & 22 & 33 & - & 30 & WNK-4 protein kinase \\
\hline jfh-453 & ROLCLRADIS]*FKGISD & AT1G71710 & 18 & 6 & - & 30 & Inositol polyphosphate 5-phosphatase \\
\hline jfh-439 & RPFWARTE[S]GIFRAV & AT2G41140 & 6 & - & - & 26 & CRK1, CPK-related kinase \\
\hline jfh-531 & RRVLERLD[S] ${ }^{*}$ DLOKLE & AT4G02710 & 7 & - & - & 25 & Kinase Interacting Protein \\
\hline jfh-520 & RPFYGRTE[S]AIFRCV & AT3G49370 & 8 & 4 & - & 24 & CRK6, CPK-related kinase \\
\hline jfh-452 & QLLREI[S]*RRGLVANa & AT1G64100 & 8 & 12 & - & 23 & Pentatricopeptide (PPR) repeat- protein \\
\hline jfh-548 & FGMPKRSR[S]*FGDVNE & AT4G32285 & 7 & - & - & 23 & Clathrin assembly protein-related \\
\hline jfh-495 & DRWLFRKTPIS]FLWRS & АT3G05200 & 16 & - & 10 & 22 & ATL6, zinc finger protein \\
\hline jfh-512 & DYRFVRSP[S]* LSLASL & AT3G25500 & 9 & 16 & - & 22 & Formin-like protein AHF1 \\
\hline jfh-542 & FGTRLSRSI[S]* EANIA & AT4G23640 & 6 & 5 & - & 22 & $\mathrm{TRH} 1, \mathrm{~K}$ transporter \\
\hline jfh-494 & DRWAFLRNA[S] ${ }^{*}$ FLWRN & АT3G05200 & 11 & 6 & - & 21 & ATL6, zinc finger protein \\
\hline jfh-532 & QGVTRVN[S]* LVOLPRF & AT4G03415 & - & 8 & 5 & 20 & $\mathrm{PP} 2 \mathrm{C}$, protein phosphatase \\
\hline jfh-579b & VRRFDRTS[S] ${ }^{*}$ AAIHAL & AT5G47910 & 6 & 8 & - & 20 & RBOH-D NADPH oxidase \\
\hline jfh-533 & RSSLSRAS[S]* SVSTLY & AT4G03550 & 14 & 5 & - & 20 & Glucan synthase component \\
\hline jfh-497 & VELMRRVVIS]*FONPRV & АT3G06450 & 7 & - & - & 20 & Anion exchanger \\
\hline jfh-550 & HVSRLARAS[S]*TEVRY & AT4G35060 & - & - & - & 20 & Unknown \\
\hline jfh-505 & RTLDRLI[S]*TGESERF & АT3G11820 & - & - & - & 20 & Syntaxin \\
\hline jfh-454 & DVKHLARSCIS]SDSVR & AT1G73080 & 6 & 4 & - & 19 & PEPR1, LRR receptor kinase \\
\hline jfh- $425^{c}$ & KHSLKRKVIS]NPSFIA & AT1G19870 & 4 & 4 & 4 & 18 & CaM-binding protein \\
\hline jfh-414 & SPRLVKSLIS]ASSFLI & AT1G07110 & 8 & 4 & - & 18 & Fructose-6-phosphate 2-kinase \\
\hline
\end{tabular}


Table 1 | Continued

\begin{tabular}{|c|c|c|c|c|c|c|c|}
\hline Peptide & Peptide sequence & AGI\# & CPK1 & CPK10 & CPK16 & СРК34 & Description \\
\hline jfh-524 & EGNVKRAN[S]* LVRSGA & АT3G52400 & - & - & - & 18 & Syntaxin \\
\hline jfh-435 & ASGPTRSSIS]FSATRS & AT1G34300 & 4 & - & - & 17 & Lectin protein kinase related \\
\hline jfh-552 & SAIKALG[S] ${ }^{*}$ FR[S]NATN & AT4G35100 & 10 & - & - & 15 & PIP2.7, Aquaporin \\
\hline jfh-583 & KTKMNKSR[S]* LYDLQE & AT5G49760 & - & 5 & - & 15 & LRR protein Kinase \\
\hline jfh-592 & VAPLARAS[S]FEVKYT & AT5G66110 & - & - & - & 13 & Metal ion binding protein \\
\hline jfh-526 & AGAIKALG[S]FRSOPH & AT3G54820 & 9 & 4 & - & 11 & PIP2.5, Aquaporin \\
\hline jfh-422d & PGAPSRSG[S]*FAGTAQ & AT1G16860 & 4 & - & - & 11 & Merozoite surface protein-related \\
\hline jfh-530 & EERYFRAD[T]* LDFSKW & AT3G63260 & - & - & - & 11 & MRK1, protein kinase \\
\hline jfh-440 & YASIRSLPIS]PRNVLI & AT1G51260 & - & - & - & 11 & Acyltransferase \\
\hline jfh-429 & GLHKLRCN[S] ${ }^{*}$ TAELNP & AT1G23080 & - & - & - & 10 & Auxin efflux carrier component \\
\hline jfh-266 & DSRILSOML[S]* OKLRP & AT5G47910 & - & - & - & 10 & RBOH-D NADPH oxidase \\
\hline jfh-149 & RTAFLSQY[S] ${ }^{*}$ FYKSLL & AT5G44240 & 5 & - & - & 9 & ALA2, P-type Lipid Flippase \\
\hline jfh-415 & RERYOKO S [S]LL SKLT & AT1G10290 & 5 & - & - & 9 & ADL6, Dynamin-like protein \\
\hline jfh-490 & EQKMSSIE[S]*FKOSSL & AT2G47000 & 4 & - & - & 9 & $\mathrm{ABC}$ transporter \\
\hline jfh-544 & SRRRLSRPG[S]GSVSG & AT4G25970 & - & - & - & 9 & Phosphatidylserine Decarboxylase 2 \\
\hline jfh-545 & FQRLERRQ[S]*VEVWP & AT4G27060 & - & - & - & 9 & Microtubule-associated protein \\
\hline jfh-442 & NRKLEKMA[S]*IDVHLR & AT1G53310 & - & - & - & 9 & PEP carboxylase \\
\hline jfh-445 & PPPIDRNK[ S] ${ }^{*}$ FDDEDS & AT1G53730 & 5 & - & - & 8 & LRR protein kinase \\
\hline jfh-575 & PREMGRNL[S] ${ }^{*}$ GKAETM & AT5G41950 & 4 & - & - & 8 & Expressed protein \\
\hline jfh-455e & IVYRASLG[S]GKVYAV & AT1G73080 & - & - & - & 6 & Receptor-like protein kinase \\
\hline jfh-423 & SVSMKKTN[S]GPLSKH & AT1G16860 & - & - & - & 5 & Merozoite surface protein related \\
\hline jfh-244 & IRRDR[S]VDKNDIS]NGD & АT3G55940 & - & 4 & - & - & Phospholipase C \\
\hline jfh-447 & FSSGSRRTQ[S]VNDDE & AT1G59870 & - & 4 & - & - & PDR8, ABC transporter \\
\hline jfh-124 & NNTLKKSVSSPFMNT & AT1G77760 & 4 & - & - & - & Nitrate reductase \\
\hline \multicolumn{8}{|c|}{ PEPTIDES BASED ON PREDICTED SITES } \\
\hline jfh-319 & RSLFKGSRSPSLKKP & АT3G63380 & 5 & 12 & - & 33 & ACA12, P-type calcium pump \\
\hline jfh-296 & ASRELRRVFSRRPSP & AT5G47910 & 4 & 18 & - & 27 & RBOH-D, NADPH oxidase \\
\hline jfh-097 & RYRRMERTSSMPRAS & AT2G32400 & 10 & 17 & 8 & 24 & GLR 3.7, glutamate receptor \\
\hline jfh-317 & SDFLKRLLS*SGMNPN & AT5G37500 & 9 & 13 & - & 23 & GORK, K-channel \\
\hline jfh-476 & RENFVRLDS*MDSRYS & AT2G23980 & 10 & - & - & 22 & CNGC6, cyclic nucleotide gated channel \\
\hline jfh-294 & KFVRLDS*MDSRYSQT & AT4G30560 & 6 & - & - & 21 & CNGC9, cyclic nucleotide gated channel \\
\hline jfh-287 & PMVITRSESSSRLRS & AT1G15990 & 9 & 11 & - & 18 & CNGC7, cyclic nucleotide gated channel \\
\hline jfh-624 & YKRRKLAKELS*LHEA & AT5G14870 & 6 & - & - & 17 & CNGC18, cyclic nucleotide gated channel \\
\hline jfh-071 & SGGHS*RRYSDPAQNG & AT1G59610 & - & - & 6 & 12 & ADL-3, Dynamin-like protein \\
\hline jfh-142 & AAKAITRLQSLPSGS & AT1G09570 & - & - & - & 11 & Phytochrome A \\
\hline jfh-307 & KAPAHLGS*SRDYNVD & AT2G44100 & - & - & - & 10 & RAB-GDP dissociation inhibitor \\
\hline jfh-625 & KLAKELSLHESSGYY & AT5G14870 & - & - & - & 9 & CNGC18, cyclic nucleotide gated channel \\
\hline
\end{tabular}


Table 1 | Continued

\begin{tabular}{llllllll}
\hline Peptide & Peptide sequence & AGI\# & CPK1 & CPK10 & CPK16 & CPK34 & Description \\
\hline jfh-767 & NDKLPRVSSSDSMEA & AT1G52240 & - & - & - & 7 & ROP-GEF11, guanyl-nucleotide exchange factor \\
jfh-035 & RNMERSVSSSPSSSS & AT3G01610 & - & - & - & 7 & Cell cycle control protein \\
jfh-131 & AFATTRQRTCPRASG & AT5G05340 & - & 4 & - & - & Peroxidase \\
\hline
\end{tabular}

${ }^{a}$ CPK16 did not phosphorylate the in vivo mapped site [in brackets] when the other 2 serines were mutated to alanine.

${ }^{b}$ CPK10 only phosphorylated the wild type peptide.

${ }^{\circ} \mathrm{CPK} 1$ and $\mathrm{CPK} 10$ only phosphorylated the wild type peptide.

${ }^{\circ} \mathrm{CPK} 1$ only phosphorylated the wild type peptide.

e Only the wild type peptide was phosphorylated by CPK 34 (and others when indicated).

fIn vivo mapped site [ ] is not phosphorylated by CPK34 when all other serine and threonines are mutated to alanine.

gln ach-375, $M$ was not substituted with Nleu.

hIn vivo evidence for phosphorylation of pollen paralogs based on related protein from vegetative tissue.

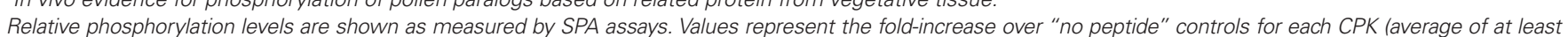

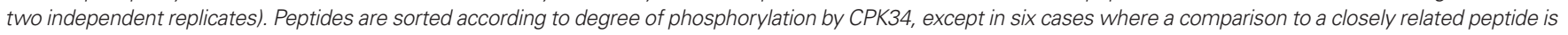

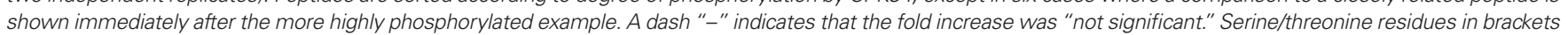

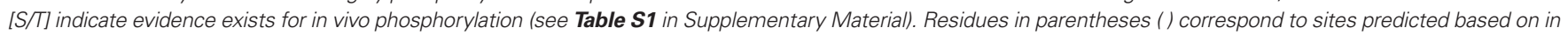

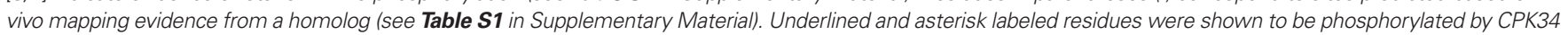

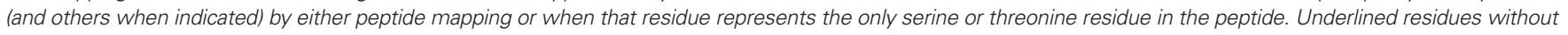

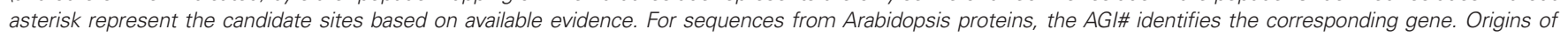
reference peptides are indicated by a PubMed Identification. Origins of all other peptides can be found in Table S1 in Supplementary Material.

a peptide's kinetic properties as a substrate. Thus, a relatively small change in cut-off thresholds could change a particular substrate's designation as a positive or negative. For this reason, selected peptides were chosen for follow-up assays to verify examples of substrate specificity (discussed below). In contrast to the SPA assays, the standard filter-based assays were done under Michaelis-Menten conditions. These assays (Tables 4 and 5) confirmed that the SPA assay conditions used here provided a reasonable indicator of a peptide's relative strength as a CPK substrate.

Of the 102 peptide substrate hits in the SPA assay, the largest subset (33) were phosphorylated by three CPKs: isoforms 1, 10, and 34. However, each of these CPKs phosphorylated a distinct subset of shared and isoform-specific peptides, supporting a conclusion that each isoform has unique substrate specificity. CPK34 had the largest number of isoform-specific substrates (31), whereas CPKs 10 and 1 had only 3 and 2 substrates, respectively.

CPK16 phosphorylated the fewest synthetic peptides (nine). The most strongly labeled peptides included two peptides from a ubiquitin ligase (ATL6, AT3G05200, peptides jfh-495 and -496) and a protein of unknown function (AT3G27390, peptide jfh-515), all three of which contained a putative CPK site identified through mapping surveys of in vivo phosphorylated proteins. Another was jfh-097, a peptide containing a predicted 14-3-3 binding site from a glutamate receptor 3.7 (AT2G32400), previously identified as a 14-3-3 interactor (Chang et al., 2009). The only reference peptide to show significant labeling was the non-plant peptide sequence MARCKS (ach-400).

Of the nine synthetic peptide substrates for CPK16, all were phosphorylated by at least one of the other three CPKs tested (i.e., substrates were not CPK16-specific). However, because each of these peptides contain multiple serines, it was not clear if CPK16 recognized the same or a different phosphorylation site. In one case (peptide jfh-097), Edman degradation was used to confirm that the same serine could be phosphorylated by CPK16 and CPK34 [in the tryptic fragment, RTS(pS)MP]. This site matched a "simple-1" consensus motif, indicating that CPK16 is not restricted to a "simple-2" consensus site (like the S109 site of Di19-2, Figure 4).

\section{IDENTIFICATION OF PHOSPHO-SITES BY "PEPTIDE MAPPING" WITH ALANINE SUBSTITUTIONS}

Because most of the 102 synthetic peptide hits contained multiple Ss or Ts, the specific phosphorylation site(s) could not be assigned from the initial survey reactions. For a subset of positive hits, additional mutant peptides were synthesized in which selected S or T residues were replaced with alanines. Using this approach, 43 phospho-sites were mapped to a specific S or T (indicated by an asterisk in Table 1). An additional 12 peptides contained only a single $S$ or T, in a total of 55 peptides in which specific phospho-sites were established. Of these, only one site did not conform to either a "simple-1" consensus site [basic-X-X-(S/T)] or a "simple-2" site [(S/T)-Xbasic]. The exception was jfh-149 (RTAFLSQY[S]*FYKSLL), which was derived from an in vivo-mapped phospho-site in a lipid flippase, ALA2 (Harper lab, unpublished). However, the low frequency of non-consensus sites does not necessarily indicate that CPKs are more likely to conform to these simple consensus sites, as nearly all the peptides tested here were selected because they already contained a proposed CPK consensus site.

This "mutant-peptide" mapping strategy also corroborated significant differences in substrate specificity determinants for each of the CPKs tested. For six peptides with various alanine-substituted versions, differential effects on substrate recognition were observed among CPKs 1, 10, and 34 (Table 2). In eight cases, recognition by two of the three isoforms was lost, and in four cases recognition was lost by only one isoform. For example, a mutant version of jfh-579 (i.e., jfh-688) revealed a disruption of phosphorylation by CPK10, but not by CPK1 and CPK34; and a mutant version of jfh-458 (i.e., jfh-723) provided a disruption of phosphorylation by CPK1, but not by CPK34.

Table 3 shows SPA results for variations on peptide jfh-515, which was recognized by all four CPKs tested, including CPK16. This peptide contained three Ss, the central one identified as an in vivo phosphorylation site. By mutating the central S (jfh-734), we found that at least one of the flanking Ss was still labeled by all four CPKs. However, when both flanking S residues were changed to 
alanine (leaving only the central mapped pS; peptide jfh-735), phosphorylation occurred with CPKs, 1, 10, and 34, but not with CPK16. The failure of CPK16 to recognize this double alanine-substituted version is consistent with it having distinct substrate specificity.

\section{EXAMPLES OF KINETIC DIFFERENCES BETWEEN CPKs 16, 1, 10, AND 34}

To confirm the qualitative differences observed here for substrate specificity among the four CPKs tested, we compared reactions with selected substrates and kinases for differences in $K_{\mathrm{M}} \mathrm{s}, k_{\text {cat }} \mathrm{s}$, and catalytic efficiencies under standard Michaelis-Menten conditions.

In analyses using three peptides recognized by CPK16 and 34 (jfh-097, ach-400, and jfh-515), significant differences where observed in multiple kinetic parameters (Table 4). For each substrate, reactions with CPK16 showed significantly weaker $K_{\mathrm{M}} \mathrm{s}$ (as much as 40-fold) compared to CPK34. However, CPK16 reactions showed higher turnover rates $\left(k_{\text {cat }}\right)$, resulting in catalytic efficiencies for CPK34 and CPK16 that were within five-fold of each other. For CPK16, the best catalytic efficiency was observed with the ach-400 peptide (MARKS), which was approximately five-fold greater than with CPK34.

Similar kinetic differences were observed in reactions comparing two peptides recognized by CPKs 1, 10, and 34 (ach-393/syntide-2 and jfh-597; Table 5). The peptide jfh-597 was derived from a $\mathrm{K}^{+}$ channel, GORK (jfh-317), and is modified with an alanine substitution that leaves a single $S$ residue corresponding to the location of a phospho-S in a potential 14-3-3 binding site. Consistent with the

Table 2 | Substrates from "peptide mapping" of phosphorylation sites revealing substrate specificity differences among CPK1, 10 , and 34.

\begin{tabular}{|c|c|c|c|c|c|}
\hline Peptide\# & \multicolumn{3}{|c|}{ Phosphorylation by } & Peptide sequence & Description \\
\hline jfh-753 & - & - & 9 & LRELTKKSA (a) FLRAV $\underline{S}$ & Mutant of jfh-752 \\
\hline jfh-754 & 18 & - & 33 & LRELaKaA ( $\underline{\mathbf{S}})$ FLRAVa & Mutant of jfh-752 \\
\hline jfh-579 & 6 & -8 & 20 & VRRFDRTS [S] AAIHAL & RBOH-D NADPH oxidase \\
\hline jfh-689 & - & - & - & VRRFDRTS [a] AAIHAL & Mutant of jfh-579 \\
\hline jfh-287 & 9 & - & 18 & PMVITRSE ( S ) SSRLRS & CNGC7, cyclic nucleotide gated channel \\
\hline jfh-636 & - & - & 6 & PMVIaRaE (a) as & Mutant of jfh-287 \\
\hline jfh-637 & - & - & 6 & PMVIaRaE (a) $\underline{\mathbf{S}}$ aRLRa & Mutant of jfh-287 \\
\hline jfh-638 & - & - & 13 & PMVIaRaE ( $\underline{\mathbf{S}})$ aaRLRa & Mutant of jfh-287 \\
\hline jfh-639 & - & - & - & PMVIaR $\underline{\mathbf{S}}$ E (a) aaRLRa & Mutant of jfh-287 \\
\hline jfh-705 & - & - & 15 & KHaLKRKV $[\underline{\mathbf{S}}]$ NPaFIA & Mutant of jfh-425 \\
\hline jfh-422 & 4 & - & 11 & PGAPSRSG [ $\mathbf{S}$ ] FAGTAQ & Merozoite surface protein-related \\
\hline jfh-697 & - & - & - & PGAP $\underline{S} R \underline{S} G$ [a ] FAG $\underline{T} A Q$ & Mutant of jfh- 422 \\
\hline jfh-698 & - & - & 6 & PGAPaRaG $[\underline{\mathbf{S}}]$ FAGaAQ & Mutant of jfh-422 \\
\hline jfh-458 & 5 & - & 10 & NAPIQRSS [S] TLLKMR & Mechanosensitive ion channel \\
\hline jfh-722 & - & - & - & NAPIQRSS $[a] \underline{T} L L K M R$ & Mutant of jfh-458 \\
\hline jfh-723 & - & - & 10 & NAPIQRaa $[\underline{\mathbf{S}}]$ aLLKMR & Mutant of jfh-458 \\
\hline
\end{tabular}

Relative phosphorylation levels are shown as determined by a standard SPA assay. Values shown represent the average of at least two independent assays. Position of predicted or in vivo mapped sites are designated by ( ) or [ ] respectively. Underlined residues in mutant peptides show potential phosphorylation sites. S or TS with evidence of phosphorylation are shown in bold. Small case "a" indicates an S to A substitution.

Table 3 | "Peptide mapping" of phosphorylation sites in substrate jfh-515 provides evidence for a substrate specificity difference between CPK16 and CPKs 1, 10, and 34

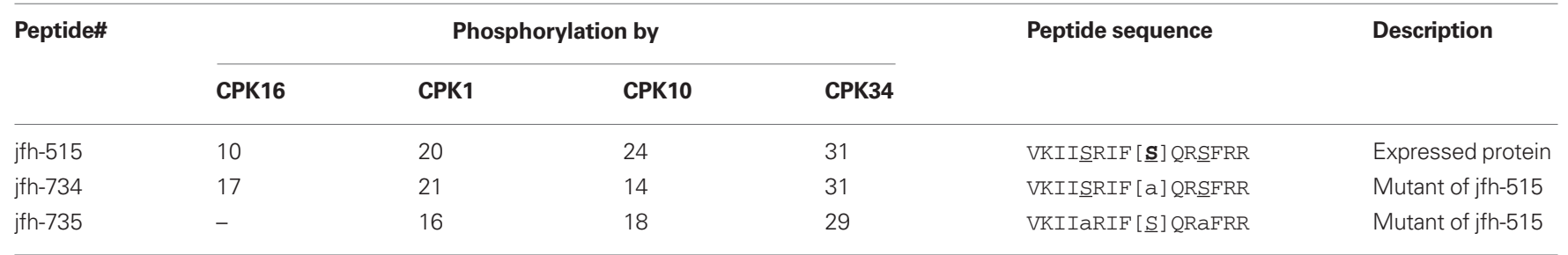

Relative phosphorylation levels are shown as determined by a standard SPA assay. Values shown represent the average of at least two independent assays. The in vivo mapped phosphorylated $S$ is denoted as [S] in bold. Potential phosphorylation sites are underlined. Small case "a" indicates an S to A substitution. 
Table 4 | CPK16 and 34 show kinetic differences in the phosphorylation of three shared peptide substrates.

\begin{tabular}{lllll}
\hline Peptide \# & \multicolumn{3}{c}{ Kinase } & Catalytic efficiency \\
\cline { 2 - 4 } & CPK & \multicolumn{1}{c}{$\boldsymbol{K}_{\mathrm{M}}(\boldsymbol{\mu} \mathrm{M})$} & \multicolumn{1}{c}{$\boldsymbol{K}_{\text {cat }}$} \\
\hline jfh-97 & 16 & 152,94 & 3734,2677 & 25,29 \\
& 34 & 26,28 & 502,718 & 19,26 \\
ach-400 & 16 & 108,119 & 1795,1429 & 17,12 \\
& 34 & $6.0,6.6$ & 398,541 & 66,82 \\
jfh-515 & 16 & 208,173 & 5114,4854 & 25,28 \\
& 34 & $5.3,5.4$ & 223,231 & 41,43 \\
\hline
\end{tabular}

The $k_{\text {cat }}$ is represented as nmol phosphate incorporated/min/mg CPK. Catalytic efficiency is $k_{c a t} / K_{M^{\prime}}$ expressed as nmol phosphate incorporated/min/mg enzyme/ $\mu \mathrm{M}$ substrate. Results are shown from two independent reactions performed using a filter assay method.

Table 5 | CPK1, 10, and 34 show kinetic differences in the phosphorylation of two shared peptide substrates.

\begin{tabular}{lllll}
\hline Peptide \# & \multicolumn{3}{c}{ Kinase } & Catalytic efficiency \\
\cline { 2 - 4 } & CPK & $\boldsymbol{K}_{\mathrm{M}}(\boldsymbol{\mu} \mathbf{M})$ & $\boldsymbol{k}_{\text {cat }}$ \\
\hline ach-393 & 1 & 49,60 & 362,482 & $7.5,8.0$ \\
& 10 & 238,244 & 252,217 & $1.1,0.9$ \\
& 34 & 65,76 & 155,225 & $2.4,3.0$ \\
jfh-597 & 1 & 84,86 & 5790,5900 & $69.0,69.0$ \\
& 10 & 35,37 & 1264,1639 & $36.3,43.9$ \\
& 34 & $8.5,8.9$ & 475,614 & $55.9,68.9$ \\
\end{tabular}

Substrates are syntide-2 (ach-393) and a mutant version of the GORK peptide (jfh-597, aDFLKRLLSaGMNPN, with only a single phosphorylation site "S"). Values for kcat are represented as nmol phosphate incorporated/min/mg enzyme. Catalytic efficiency is $k_{c a t} / K_{M}$ expressed as $n m o l$ phosphate incorporated/min/ $\mathrm{mg}$ enzyme/ $\mu \mathrm{M}$ substrate. Results are shown from two independent reactions using a filter assay method.

notion that each of these CPKs has different substrate specificities, each peptide/kinase reaction displayed diverse kinetic parameters, with as much as a 10 -fold difference in $K_{\mathrm{m}} \mathrm{s}$ and $k_{\text {cat }} \mathrm{s}$, and a two- to eight-fold range in catalytic efficiencies.

\section{DISCUSSION}

\section{SUBSTRATE SPECIFICITY DIFFERENCES FOR CPKs 1, 10, 16, AND 34}

CPK isoforms $1,10,16$, and 34 represent 4 of the 12 different subgroups of CPKs found in flowering plants (Harper et al., 2004). Three lines of evidence presented here support a model in which CPKs from different subgroups are likely to have functionally distinct substrate specificities. First, each of the four CPKs recognized unique subsets of substrates (see the 102 peptides in Table 1 and protein Di19-2 in Figure 1). Second, alanine substitutions in seven selected peptides uncovered different substrate recognition determinants for each of the four kinases (Tables 2 and 3). Finally, kinetic analyses using five selected peptides showed more than 10-fold differences in $K_{\mathrm{M}} \mathrm{s}$ and $k_{\text {cat }} s$ for each of the four different CPKs (Tables 4 and 5).

The most distinct substrate specificity was observed for CPK16 (Table 1 and Figure 1). CPK16 is a representative of the most divergent subgroup of CPKs in Arabidopsis. In this subgroup, the kinase domains are more similar to a family of CPK-related kinases (CRKs) than to the core group of 31 other Arabidopsis CPKs (Harper et al., 2004). Nevertheless, CPK16 displays $\mathrm{Ca}^{2+}$-stimulated activity (Figure 3 ) and contains a typical calmodulin-like regulatory domain - the structural feature that initially defined the CPK family.

CPK16's unique substrate specificity was revealed initially by analysis of a Di19-2 fusion protein. This fusion protein was strongly phosphorylated by CPK16, but more weakly by CPK1, 10, or 34 (Figure 1). A fusion protein G-S109-ST2 was engineered to display just one of the CPK16 sites present in the Di19-2 protein. This substrate had a $K_{\mathrm{M}}$ of $70 \mu \mathrm{M}$ in reactions with CPK16, but failed to show any significant phosphorylation by the other three CPKs. In contrast, CPK16 only weakly recognized a site from NR, which was strongly phosphorylated by the other three kinases (Figure 1). This comparison showed that CPK16 had a substrate preference contrary to that of CPKs 1,10 , and 34 . In another recent study, NR was found to be a good substrate for AtCPK isoforms 17 and 2, but not for CPKs 16, 24, or 29 (Lambeck et al., 2010). This supports the expectation that CPK16 and other CPKs will show significant differences in substrate specificity.

The extent to which the substrate specificity of CPK16 differed was further demonstrated here by a survey of 534 unique peptide substrates (Table 1). From the 102 synthetic peptide hits that were identified as in vitro substrates for at least one of the four CPKs, only nine showed significant phosphorylation by CPK16. By comparison, the next lowest number of substrates identified, 41 , was found for CPK10. While all nine synthetic peptide substrates for CPK16 were also recognized by CPK34, the presence of multiple $\mathrm{S} / \mathrm{Ts}$ in each peptide leaves open the possibility that each enzyme might still recognize other sites within a given peptide.

Substrate specificity differences were also revealed by comparison of CPK1, 10, and 34. In the survey of peptide substrates using an SPA assay (Table 1), CPK34 had the highest number of isoform-specific substrates (32), whereas CPK10 had only three. While CPK1 showed only two isoform-specific substrates, its 64 positive substrate hits were a unique mixture of those recognized by the other three isoforms. In follow-up assays on five peptides, a comparison of kinetic parameters with each of the CPKs illustrated reactions showing greater than 10-fold differences in $K_{\mathrm{M}} \mathrm{s}$ and $k_{\text {cat }} \mathrm{s}$ (Tables 4 and 5). This indicates that each of these four enzymes have significant differences in substrate recognition and turnover (i.e., substrate specificity).

\section{THE MOLECULAR BASIS OF SUBSTRATE SPECIFICITY DIFFERENCES}

The structural basis for CPK substrate recognition is not yet clear. Multiple features of the kinase might contribute to specificity, from various amino acid residues associated with the substrate binding groove in the kinase domain, to various features associated with the $\mathrm{N}$ - and C-terminal domains interacting with substrates. For $\mathrm{NtCDPK} 1$, the variable $\mathrm{N}$-terminal domain can be transferred to AtCPK9, thereby altering the substrate specificity of CPK9 to match that of CDPK1 (Ito et al., 2010). The crystal structures of apicomplexan CPKs suggest a possible interaction of the C-terminal regulatory domain with a "latch" in the N-terminal domain (Wernimont et al., 2010,2011). All of the intramolecular interactions that occur during activation of a CPK might also influence substrate recognition and turnover kinetics. 
It is also important to emphasize that the kinase assays here were based on recombinant proteins with $\mathrm{N}$ - and C-terminal modifications. Although each recombinant kinase had a similar fusion protein design, their respective enzyme kinetics might differ from their native enzyme counterparts under in vivo conditions.

\section{BIOLOGICAL RELEVANCE OF SUBSTRATE SPECIFICITY DIFFERENCES}

The isoform-specific functions of CPKs are potentially influenced by features that control their subcellular location, protein-complex interactions, lipid and $\mathrm{Ca}^{2+}$ activation kinetics, and substrate specificity. This study was aimed at evaluating the potential influence of substrate specificity.

The extent to which CPKs in Arabidopsis are functionally interchangeable has yet to be determined. However, a consideration of pollen-expressed CPKs provides examples of both redundant and non-redundant activities (Yoon et al., 2006; Myers et al., 2009). For example, a double disruption of Arabidopsis CPK17 and 34 results in a nearly sterile phenotype with pollen tubes showing deficiencies in growth rate, growth potential, and tropism toward ovules (Myers et al., 2009). Because single disruptions in either CPK17 or 34 alone did not show any detectable phenotypes, this pair of CPKs provides an example of functional redundancy. Nevertheless, expression in pollen of 10 other CPKs is not able to compensate for the double knockout of CPK17 and 34. Specifically, one such exogenous kinase, CPK16, is also highly expressed in pollen and is targeted to a similar plasma membrane location (Dammann et al., 2003) as CPK17 and 34 (Myers et al., 2009), but is not able to restore the double loss of function.

While multiple features are expected to make different CPKs functionally distinct, results here suggest that substrate specificity differences could make a significant contribution. In vivo support for this expectation comes from a recent study on NtCDPK1 in which in vitro phosphorylation of a substrate (transcription factor RSG) was shown to be dependent on the variable N-terminal domain of the kinase (Ito et al., 2010). When the N-terminal domain of NtCDPK1 was substituted for the analogous region in a different CPK (AtCPK9), the chimeric kinase displayed in vitro and in vivo activities similar to that of NtCDPK1.

\section{DI19-2, A CPK16-SPECIFIC SUBSTRATE}

Of the candidate phosphorylation sites identified here for CPK16, the S109 site in Di19-2 was the most extensively analyzed. Although this site overlaps with both simple- 1 and simple- 2 consensus sites for CPKs (Harper and Harmon, 2005), it was not recognized by three other isoforms, CPK1, 10, and 34 -emphasizing that features beyond a simple consensus site are clearly important for substrate recognition by different CPKs.

Di19-2 belongs to a family of seven related proteins in Arabidopsis, structurally defined by the presence of two atypical zinc finger domains. The Di19 name derives from a founding member whose mRNA expression was observed to be drought-induced. While the biological function of Di19-2 is not known, evidence indicates that its mRNA expression can be induced by a salt stress (but not drought stress; Rodriguez Milla et al., 2006). Public domain expression profiling results indicate that it is expressed in all major plant tissue types, including pollen, suggesting a function of potential importance to a subset of stress tolerance pathways in most cell types. Di19-2 is thought to be present in both nuclear and cytosolic locations, as indicated by DsRED2 tagging experiments (Milla et al., 2006). Because CPK16 appears to be located at the plasma membrane, the phosphorylation of cytosolic Di19-2 might provide a pathway to relay $\mathrm{Ca}^{2+}$ signals from the plasma membrane to the nucleus. The observed $70 \mu \mathrm{M} K_{\mathrm{M}}$ for the phosphorylation of the S109 site by CPK16 is consistent with substrate affinities expected for biologically relevant phospho-regulation (Harper et al., 2004). Interestingly, Di19-2 is not recognized as a good substrate by at least five other CPKs isoforms, including 1, 10, 34 (Figure 1), 3, and 11 (Milla et al., 2006). In contrast, the other five members of the Di19 family in Arabidopsis were shown to be good substrates for multiple CPK isoforms. Thus, a potential CPK-mediated phosphoregulation of Di19-2 may require a CPK16-like substrate specificity.

\section{MODULATION OF PHOSPHORYLATION BY METHIONINE OXIDATION}

The Huber lab recently documented an example of a CPK phosphorylation site in NR (similar to peptide jfh-225) in which phosphorylation is blocked by the oxidation of a flanking methionine (e.g., $\mathrm{P}+4$ position; Hardin et al., 2009). Because thioether groups of methionines can be oxidized to sulfoxide groups by ROS such as $\mathrm{H}_{2} \mathrm{O}_{2}$, this modification (termed MetSO) provides a mechanism to transform an ROS signal into an on-off switch for a specific phosphosignaling pathway. Because plant cells have enzymes that can reduce MetSO back to Met, this regulatory switch is potentially reversible.

Of the 102 synthetic peptide substrates identified here for CPKs, 24 have methionines near the phosphorylation site. However, it is important to note that with one exception, each of the synthetic peptides used here was designed with a norleucine substitution of methionines to prevent MetSO formation. This might have altered recognition of certain sites by specific CPKs. For example, while CPK34 failed to phosphorylate a site in a peptide containing two norleucine substitutions for its methionines (GmSAT S367 ach-376), it showed strong phosphorylation of the same sequence synthesized with both methionines left unsubstituted (ach-375; Table 1). This failure of CPK34 to recognize the norleucine-substituted peptide is in contrast to $\mathrm{CPK} 1$, which retained strong phosphorylation of both peptides. Further analysis will be required to determine whether various CPKs will show isoform-specific differences in either increased or decreased substrate recognition as a result of MetSO-site modification.

\section{CPK CONSENSUS SITES?}

The use of consensus sites to predict kinase phosphorylation sites is sometimes useful, but often inaccurate (Que et al., 2010). Here we provide evidence for CPKs that predictions are usually wrong when based on consensus sites alone. Nearly all of the 534 peptides designed and tested in this study contained a simple-1 CPK consensus site (basic-X-X-S/T). Surprisingly, more than $80 \%$ of these peptides failed to show significant phosphorylation. While we cannot rule out that some peptides failed to be phosphorylated because of poor solubility or lack of appropriate secondary structure, analysis of selected peptides with alanine substitutions corroborate that recognition of a simple- 1 consensus site can be strongly influenced by flanking residues (e.g., Tables 2 and 3), as previously indicated (Huang and Huber, 2001; Hernandez Sebastia et al., 2004).

The differences in substrate specificity found here provide a partial explanation for the origins of more than seven different consensus sites for CPKs (Harper and Harmon, 2005). The 
development of a single meaningful consensus site for all CPKs does not appear possible, given that 4 of the 12 subgroups tested showed clear differences in substrate specificity. Thus, the evolution of bioinformatic tools for predicting potential CPK phosphorylation sites will need to incorporate a range of isoform-specific differences.

\section{THE FRONTIER: LINKING THOUSANDS OF KINASES TO THEIR TARGETS AND BIOLOGICAL FUNCTIONS}

CPKs have been proposed as multifunctional kinases, translating $\mathrm{Ca}^{2+}$ signals into the phospho-regulation of many different substrates (Harper et al., 2004; Klimecka and Muszynska, 2007). This paradigm is strongly supported here by the identification of 103 different substrates for four different CPKs (102 unique synthetic peptides, and residue S109 in Di19-2; Table 1 and Figure 1).

In this study, 274 peptides were designed, each with an in vivomapped phosphorylation site that matched a predicted CPK consensus site. Of these, 74 (27\%) were found to be phosphorylated by one of the four CPKs tested. Because CPKs have been shown to be present in most cellular locations (Dammann et al., 2003), a corroboration between in vivo and in vitro phosphorylation provides a reasonable basis for postulating that a particular in vivo phosphorylation event could have been mediated by a CPK. For example, phospho-sites identified in Table 1 support specific hypotheses implicating CPK signaling pathways in regulating diverse aspects of cellular physiology, including auxin efflux (AT3G54820), ethylene response (AT4G23640), mechanosensitive ion channels (AT1G23080), and vesicle trafficking (AT1G10290).

In Arabidopsis, phospho-proteomics is providing a rapidly expanding list of phosphorylation sites (Heazlewood et al., 2008; Durek et al., 2010) that have been mapped in proteins isolated from plant tissues, and therefore represent in vivo phosphorylation events (de la Fuente van Bentem et al., 2008; Kersten et al., 2009; Uno et al., 2009; Kyono et al., 2010; Nakagami et al., 2010; Bi et al., 2011; see database ${ }^{1}$ ). In an analysis of sites reported by (Sugiyama et al., 2008), more than 10\% include a "simple-1" CPK consensus site (Harper, unpublished analysis).

In our study using 274 in vivo-mapped sites that contained a simple-1 motif (excluding reference peptides), we observed a $27 \%$ success rate in finding a CPK that recognized the same peptide in an in vitro kinase reaction. By contrast, we observed only a $6 \%$ success rate for peptides that were designed without any direct support from in vivo mapping data. However, given a $27 \%$ success rate as a precedent, it is reasonable to project that more than 200 additional CPK substrates might be confirmed through the application of this strategy to the nearly 8000 mapped phosphosites listed in PhosPhAt (Heazlewood et al., 2008). Because the list of in vivo-mapped phosphorylation sites is certain to expand, we project that more than 300 phosphorylation sites will soon emerge as potential points of $\mathrm{Ca}^{2+}$-dependent phospho-regulation.

The expanding list of CPK substrates is now shifting the scientific frontier from a focus on simply identifying potential CPK phosphorylation sites, to the larger question of understanding the biological functions associated with hundreds of $\mathrm{Ca}^{2+}$-triggered changes in phosphorylation.

${ }^{1}$ http://phosphat.mpimp-golm.mpg.de/index.html

\section{MATERIALS AND METHODS KINASE EXPRESSION CLONES}

The four kinases used in this study were AtCPK1 (At5g04870), AtCPK10 (At1g18890), AtCPK16 (At2g17890), and AtCPK34 (At5g19360). Sequences for all previously unpublished clones are provided in Table S2 in Supplementary Material. For production of fusion proteins in E. coli, all clones were made as cDNAs subcloned into a pGEX expression vector with a GST N-terminal affinity tag, and modified to include a C-terminal 6x His tag (Binder et al., 1994). All expression vectors harbored an ampicillin resistance gene. Clones G-CPK34-6H (ps897) and G-CPK1-6H (ps553, also called AK1-6H) were previously described (Vitart et al., 2000a,b; Myers et al., 2009). For G-AtCPK16-6H (ps449) and G-CPK10-6H (ps1066), cDNA was PCR-amplified from a SuperScript Arabidopsis cDNA Library (Life Technologies, Carlsbad, CA, USA) with primers that included restriction sites suitable for subcloning.

\section{SUBSTRATE EXPRESSION CLONES}

G-Di19-2 (ps1195) encodes a full-length AtDi19-2 (At1g02750) cDNA cloned in a $p G E X 4 T$-1 vector to provide an N-terminal GST affinity tag (Rodriguez Milla et al., 2006).

G-GFP-ST (ps627) is a parental vector used for substrate clones described below. It is modified from a $p G E X$ backbone that encodes a N-terminal GST affinity tag, and includes a GFP, a polylinker with $A s c \mathrm{I}$ and Not I cloning sites, and a C-terminal Strep-II affinity tag.

G-GFP-S109-ST (ps1160) encodes a short sequence of Di19-2 surrounding the S109 phosphorylation site (the amino acid sequence for the S109 site shown in Figure 2). This construct was modified from ps627 by insertion of a DNA fragment from Di19-2 into the AscI/NotI site. Using ps1160, variations were made to produce the mutations shown in Figure 4.

G-GFP-NR-ST (ps699) is identical to ps1160 except that it has an insert that replaces the Di19-2 S109 site (sequence between AscI and NotI) with a sequence from a NR (NR site shown in Figure 2). G-RFP-NR-ST (ps630) was used in some experiments to provide an alternative RFP-tagged (in place of GFP) version of the same NR substrate sequence encoded in ps699.

\section{RECOMBINANT PROTEIN EXPRESSION AND PURIFICATION}

All kinase fusion proteins were purified as affinity sandwiches using a $6 \mathrm{x}$ His tag at the C-terminal end and a GST tag at the N-terminal end (Harper et al., 1994). For substrate fusion proteins encoded by G-Di19-2 $S 109$ (including mutants) and G-GFP-NR-ST, each protein was affinity-purified by a GST tag at the N-terminal end, followed by a Strep-tag-2 (IBA Biotechnology) at the C-terminal end. The fusion protein encoded by G-Di19-2 (ps1195) was purified using a GST affinity tag as described (Rodriguez et al., 2006). Purified proteins were stored frozen at $-20^{\circ} \mathrm{C}$ in $100 \mathrm{mM}$ Tris- $\mathrm{HCl}, \mathrm{pH} 8.5$, $0.1 \mathrm{mM}$ EDTA, $10 \mathrm{mM}$ glutathione, and 50\% glycerol. The concentration of each sample was determined via the Bradford method (Bradford, 1976), and purity evaluated by separation using SDS-PAGE (10\% polyacrylamide gel) and staining with Coomassie Brilliant Blue. All kinase fusions were estimated to be greater than $90 \%$ pure. 


\section{SYNTHETIC PEPTIDE DESIGN AND PRODUCTION}

Non-biotinylated syntide-2 was purchased from Bachem (Torrance, CA, USA). Other synthetic peptides were made by Sigma Genosys (St. Louis, MO, USA) with purities estimated at 50\%. Peptides used in SPA assays were all made with an N-terminal biotin group. Unless specifically noted, a norleucine was substituted for every methionine. Peptides were designed based on sequences known or predicted to be CPK substrates, as described in the results section.

\section{KINASE ACTIVITY GEL-BASED ASSAYS}

In vitro kinase assays were performed and modified as previously described (Rodriguez Milla et al., 2006) and labeled proteins separated by SDS-PAGE. Briefly, $50 \mu \mathrm{M}$ ATP (spiked with $2.5 \mu \mathrm{Ci}$ gamma- ${ }^{32} \mathrm{P}$ (3000 Ci/mmol, MP Biomedicals, Solon, OH, USA) was added to start the kinase reaction (final volume $10 \mu \mathrm{L}$ ) which consisted of $1 \mathrm{ng} / \mu \mathrm{L}$ purified $\mathrm{CPK}, 100 \mathrm{ng} / \mu \mathrm{L}$ fusion protein substrate, and standard kinase reaction buffer $(20 \mathrm{mM}$ Tris- $\mathrm{HCl} \mathrm{pH}$ 7.5, $10 \mathrm{mM} \mathrm{MgCl}_{2}, 1 \mathrm{mM}$ EGTA, $1.1 \mathrm{mM} \mathrm{CaCl}_{2}$ ). The reactions were incubated for $10 \mathrm{~min}$ at RT and stopped by adding $10 \mu \mathrm{L} 2 \mathrm{X}$ SDS sample buffer. Proteins were separated by $12 \%$ SDS-PAGE and the gel was air-dried between acetate sheets. The dried gel was processed using either a phosphorimager (Cyclone Storage Phosphor System, PerkinElmer, Boston, MA, USA) or exposure to X-ray film (GE Healthcare Biosciences, Piscataway, NJ, USA). Images were processed using Quantity One (Bio-Rad) to determine the relative intensity of labeling. Signals were normalized to the amount of protein as determined from Coomassie Brilliant Bluestained gels after SDS-PAGE.

\section{PHOSPHORYLATION OF SYNTHETIC PEPTIDES USING SCINTILLATION PROXIMITY ASSAY}

Synthetic peptides with N-terminal biotin tags were resuspended in $50 \%$ acetonitrile to a final stock concentration of approximately $5 \mathrm{mM}$. Kinase reaction conditions consisted of $20 \mu \mathrm{M}$ peptide (or $\mathrm{ddH}_{2} \mathrm{O}$ as a control), $10 \mu \mathrm{M}$ ATP, $0.0625 \mu \mathrm{Ci}^{33} \mathrm{P}[\gamma$-ATP $], 25$ ng purified CPK, and $0.1 \mathrm{mg} / \mathrm{mL}$ BSA (Bovine Serum Albumin) in standard kinase buffer (10 mM Tris- $\mathrm{HCl}, \mathrm{pH} 7.5,1 \mathrm{mM} \mathrm{MgCl}_{2}, 1.1 \mathrm{mM}$ $\mathrm{CaCl}_{2}, 1 \mathrm{mM}$ EGTA) in a final reaction volume of $25 \mu \mathrm{L}$. Reactions were started by addition of ATP. After $24 \mathrm{~min}$ incubation at RT, $10 \mu \mathrm{L}$ aliquots were diluted with $30 \mu \mathrm{L}$ dilution buffer $(0.13 \%$ SDS, $13.3 \mathrm{mM}$ EDTA) and $10 \mu \mathrm{L}$ of this dilution was added to $200 \mu \mathrm{L}$ pre-aliquoted stop solution $(500 \mu \mathrm{M}$ ATP, $1 \%$ Triton $\mathrm{x}-100,1 \times \mathrm{PBS}$ $\mathrm{pH} 11.0$, and $100 \mu \mathrm{g}$ SPA beads [streptavidin-coated, yttrium silicate (GE Healthcare)] in 96-well plates. Counts per minute (CPM) for each stopped reaction were determined by a microbeta scintillation counter (PerkinElmer) with a 5-750 window setting, as per manufacturer's recommendations. Those peptide reactions showing at least fourfold greater CPM than a no-peptide control (in an average of two to four independent reactions) were considered to represent significant levels of phosphorylation.

\section{STANDARD FILTER-BASED ASSAY FOR KINASE ACTIVITY}

Kinetic assays were performed essentially as described (Harper et al., 1994). Briefly, kinase reactions were started by adding ATP [final concentration of $50 \mu \mathrm{M}$ ATP plus $0.375 \mu \mathrm{Ci}{ }^{33} \mathrm{P}[\gamma$-ATP $](3000 \mathrm{Ci} /$ $\mathrm{mmol})]$ to a reaction that consisted of $1 \mathrm{ng} / \mu \mathrm{L} \mathrm{CPK}$-fusion protein, $0.1 \mathrm{mg} / \mathrm{mL} \mathrm{BSA}$, and varied peptide substrate concentrations $(0,5$,
$10,20,50,80,100$, or $200 \mu \mathrm{M}$ ) in a kinase reaction buffer (above). A typical reaction volume was $15 \mu \mathrm{L}$. The reaction was allowed to proceed at RT for $12 \mathrm{~min}$ and was stopped by spotting an $8-\mu \mathrm{L}$ aliquot onto P81 phosphocellulose chromatography paper (GE Healthcare Biosciences, Piscataway, NJ, USA). Filters were immediately immersed in $75 \mathrm{mM}$ phosphoric acid (PA), washed $4 \times 5 \mathrm{~min}$ in $150 \mathrm{~mL} 75 \mathrm{mM}$ PA, immersed in $95 \%$ EtOH for $1 \mathrm{~min}$ and airdried. Dry filters were submerged in Ecoscint (Fisher, Pittsburgh, $\mathrm{PA}$, USA) and ${ }^{33} \mathrm{P}$ counts were determined by a scintillation counter. To calculate activities in nmol $\mathrm{P}$ incorporated $/ \mathrm{min} / \mathrm{mg}$ enzyme, the total amount of ${ }^{33} \mathrm{P}$ label in reactions was determined by counting a $5-\mu \mathrm{L}$ aliquot of a sample reaction that was dried on filter paper and left unwashed. A Lineweaver-Burk method was used to determine $K_{\mathrm{M}}$ s. Results shown are from two independent protein purifications for each CPK, with each preparation assayed at least twice.

\section{PHOSPHO-SITE MAPPING}

Phosphorylation site mapping was performed as previously described (Rodriguez Milla et al., 2006). Briefly, phosphorylated protein was dried at room temperature in a speed-vac, resuspended in a trypsin solution containing $0.4 \mu \mathrm{g}$ trypsin (Promega, Madison, WI, USA) and $1 \mathrm{mM}$ DTT in $25 \mathrm{mM}$ ammonium bicarbonate, $\mathrm{pH} 8.0$, and digested for $16 \mathrm{~h}$ at $37^{\circ}$. The digested peptides were dried and then redissolved in $0.1 \%(\mathrm{v} / \mathrm{v})$ trifluoroacetic acid (TFA). Peptides were desalted using a reverse phase Zip-Tip C18 column (Millipore, Billerica, MA, USA) pre-equilibrated with 100\% (v/v) acetonitrile (ACN) and washed three times with $0.1 \%(\mathrm{v} / \mathrm{v})$ TFA. Peptides were loaded on the Zip-Tip by five cycles of aspiration and dispensing. The $\mathrm{C} 18$ column was washed with $0.1 \%(\mathrm{v} / \mathrm{v}) \mathrm{TFA}$ three times and peptides were eluted using a solution of $50 \%(\mathrm{v} / \mathrm{v})$ ACN and $0.1 \%(\mathrm{v} / \mathrm{v})$ TFA. The eluate was dried with a speed-vac.

Peptides were analyzed by a neutral loss mass spectrometry method in the UNR Proteomics Core Facility (Schroeder et al., 2004). A reverse phase C18 column (Michrom) was used to separate peptides. The program was set to perform MS/MS/MS whenever it detected neutral loss of 32.6, 38.6, 49, 58, 65, and $98 \mathrm{D}$. The $\mathrm{m} / \mathrm{z}$ values of the precursor, $y$ and $b$ ions were retrieved after the scans. Database searching was performed to identify the phosphorylated peptides. For Ion-Trap MS/MS data, $\mathrm{m} / \mathrm{z}$ values of the precursor, $y$ and $b$ ions were searched against the NCBI database by use of the TURBOSEQUEST algorithm (Thermo Scientific) or MASCOT algorithm² (Perkins et al., 1999). All MS/MS spectrum were manually inspected to assure the accuracy of the identification.

\section{ACKNOWLEDGMENTS}

This work was supported by grants to Jeffrey F. Harper from NSF (MCB-0920624, MCB-0114769, DBI-0420033, and DBI-0436450 for peptide predictions and synthesis), and NIH 1RO1 GM07081301 (for analysis of Di19-2 sites), and to Ing-Feng Chang from National Science Council, Taiwan (NSC96-3111-B-002-001 and NSC97-2311-B-002-005-MY3), and to Alice C. Harmon from NSF MCB-0114769 for peptide analysis. Mass Spectrometry and Bioinformatics were made possible by the INBRE Program of the National Center for Research Resources (NIH grant P20 RR-016464).

${ }^{2} \mathrm{http}: / / w w w . m a t r i x s c i e n c e . c o m$ 


\section{SUPPLEMENTARY MATERIAL}

The Supplementary Material for this article can be found online at http://www.frontiersin.org/plant_physiology/10.3389/ fpls.2011.00036/abstract/

\section{REFERENCES}

Arimura, G., and Maffei, M. E. (2010). Calcium and secondary CPK signaling in plants in response to herbivore attack. Biochem. Biophys. Res. Commun. 400, 455-460.

Asano, T., Hakata, M., Nakamura, H., Aoki, N., Komatsu, S., Ichikawa, H., Hirochika, H., and Ohsugi, R. (2011). Functional characterisation of OsCPK21, a calcium-dependent protein kinase that confers salt tolerance in rice. Plant Mol. Biol. 75, 179-191.

Bachmann, M., Shiraishi, N., Campbell, W. H., Yoo, B. C., Harmon, A. C., and Huber, S. C. (1996). Identification of Ser-543 as the major regulatory phosphorylation site in spinach leaf nitrate reductase. Plant Cell 8, 505-517.

Benschop, J. J., Mohammed, S., O'flaherty, M., Heck, A. J., Slijper, M., and Menke, F. L. (2007). Quantitative phosphoproteomics of early elicitor signaling in Arabidopsis. Mol. Cell Proteomics 6, 1198-1214.

Bertorello, A. M., and Zhu, J. K. (2009). SIK1/SOS2 networks: decoding sodium signals via calcium-responsive protein kinase pathways. Pflugers Arch. 458, 613-619.

Bi, Y. D., Wang, H. X., Lu, T. C., Li, X. H., Shen, Z., Chen, Y. B., and Wang, B. C. (2011). Large-scale analysis of phosphorylated proteins in maize leaf. Planta 233, 383-392.

Billker, O., Lourido, S., and Sibley, L. D. (2009). Calcium-dependent signaling and kinases in apicomplexan parasites. Cell Host Microbe 5, 612-622.

Binder, B. M., Harper, J. F., and Sussman, M. R. (1994). Characterization of an Arabidopsis calmodulin-like domain protein kinase purified from Escherichia coli using an affinity sandwich technique. Biochemistry 33 , 2033-2041.

Boudsocq, M., Willmann, M. R., Mccormack, M., Lee, H., Shan, L., He, P., Bush, J., Cheng, S. H., and Sheen, J. (2010). Differential innate immune signalling via $\mathrm{Ca}(2+)$ sensor protein kinases. Nature 464, 418-422.

Bradford, M. M. (1976). A rapid and sensitive method for the quantitation of microgram quantities of protein utilizing the principle of protein-dye binding. Anal. Biochem. 72, 248-254.

Cardenas, L. (2009). New findings in the mechanisms regulating polar growth in root hair cells. Plant Signal. Behav. $4,4-8$.

Chang, I. F., Curran, A., Woolsey, R., Quilici, D., Cushman, J. C., Mittler, R.,
Harmon, A., and Harper, J. F. (2009). Proteomic profiling of tandem affinity purified 14-3-3 protein complexes in Arabidopsis thaliana. Proteomics 9, 2967-2985.

Chehab, E. W., Eich, E., and Braam, J. (2009). Thigmomorphogenesis: a complex plant response to mechanostimulation. J. Exp. Bot. 60, 43-56.

Choi, H. I., Park, H. J., Park, J. H., Kim, S., Im, M. Y., Seo, H. H., Kim, Y. W., Hwang, I., and Kim, S. Y. (2005). Arabidopsis calcium-dependent protein kinase AtCPK32 interacts with $\mathrm{ABF} 4$, a transcriptional regulator of abscisic acid-responsive gene expression, and modulates its activity. Plant Physiol. 139, 1750-1761.

Coca, M., and San Segundo, B. (2010). AtCPK1 calcium-dependent protein kinase mediates pathogen resistance in Arabidopsis. Plant J. 63, 526-540.

Dammann, C., Ichida, A., Hong, B. Romanowsky, S. M., Hrabak, E. M., Harmon, A. C., Pickard, B. G., and Harper, J. F. (2003). Subcellular targeting of nine calcium-dependent protein kinase isoforms from Arabidopsis. Plant Physiol. 132, 1840-1848.

de la Fuente van Bentem, S., Anrather, D., Dohnal, I., Roitinger, E., Csaszar, E., Joore, J., Buijnink, J., Carreri, A., Forzani, C., Lorkovic, Z. J., Barta, A., Lecourieux, D., Verhounig, A., Jonak, C., and Hirt, H. (2008). Sitespecific phosphorylation profiling of Arabidopsis proteins by mass spectrometry and peptide chip analysis. J. Proteome Res. 7, 2458-2470.

Dodd, A. N., Kudla, J., and Sanders, D. (2010). The language of calcium signaling. Annu. Rev. Plant Biol. 61, 593-620.

Douglas, P., Moorhead, G., Hong, Y., Morrice, N., and Mackintosh, C. (1998). Purification of a nitrate reductase kinase from Spinacia oleracea leaves, and its identification as a calmodulin-domain protein kinase. Planta 206, 435-442.

Douglas, P., Pigaglio, E., Ferrer, A. Halfords, N. G., and Mackintosh, C. (1997). Three spinach leaf nitrate reductase-3-hydroxy-3-methylglutaryl-CoA reductase kinases that are required by reversible phosphorylation and/or Ca2+ ions. Biochem. J. 325(Pt 1), 101-109.

Durek, P., Schmidt, R., Heazlewood, J. L., Jones, A., Maclean, D., Nagel, A., Kersten, B., and Schulze, W.X. (2010). PhosPhAt: the Arabidopsis thaliana phosphorylation site database.

Table S1 | Peptides tested in SPA assays. Each peptide was made with norleucine substitutions for methionines (except ach-375), and a biotin tag on the $\mathrm{N}$-terminal end.

\section{Table S2 | Sequences of plasmids used in this study.}

An update. Nucleic Acids Res. 38 D828-D834.

Dvorin, J. D., Martyn, D. C., Patel, S. D. Grimley, J. S., Collins, C. R., Hopp, C. S., Bright, A. T., Westenberger, S. Winzeler, E., Blackman, M. J., Baker, D. A., Wandless, T. J., and Duraisingh, M. T. (2010). A plant-like kinase in Plasmodium falciparum regulates parasite egress from erythrocytes. Science 328, 910-912.

Franz, S., Ehlert, B., Liese, A., Kurth, J., Cazale, A. C., and Romeis, T. (2011). Calcium-dependent protein kinase CPK21 functions in abiotic stress response in Arabidopsis thaliana. Mol. Plant 4, 83-96.

Freymark, G., Diehl, T., Miklis, M., Romeis, T., and Panstruga, R. (2007) Antagonistic control of powdery mildew host cell entry by barley calciumdependent protein kinases (CDPKs). Mol. Plant Microbe Interact. 20, 1213-1221.

Gargantini, P. R., Gonzalez-Rizzo, S., Chinchilla, D., Raices, M., Giammaria, V., Ulloa, R. M., Frugier, F., and Crespi, M. D. (2006). A CDPK isoform participates in the regulation of nodule number in Medicago truncatula. Plant J. 48, 843-856.

Geiger, D., Scherzer, S., Mumm, P., Marten, I., Ache, P., Matschi, S., Liese, A., Wellmann, C., Al-Rasheid, K. A. Grill, E., Romeis, T., and Hedrich, R. (2010). Guard cell anion channel SLAC1 is regulated by CDPK protein kinases with distinct $\mathrm{Ca} 2+$ affinities. Proc. Natl. Acad. Sci. U.S.A. 107, 8023-8028.

Gleason, C., Chaudhuri, S., Yang, T., Munoz, A., Poovaiah, B. W., and Oldroyd, G. E. (2006). Nodulation independent of rhizobia induced by a calcium-activated kinase lacking autoinhibition. Nature 441 , 1149-1152.

Hardin, S. C., Larue, C. T., Oh, M. H., Jain, V., and Huber, S. C. (2009). Coupling oxidative signals to protein phosphorylation via methionine oxidation in Arabidopsis. Biochem. J. 422, 305-312.

Harper, J. F., Breton, G., and Harmon, A. (2004). Decoding $\mathrm{Ca}(2+)$ signals through plant protein kinases. Annu. Rev. Plant Biol. 55, 263-288.

Harper, J. F., and Harmon, A. (2005). Plants, symbiosis and parasites: a calcium signalling connection. Nat. Rev. Mol. Cell Biol. 6, 555-566.

Harper, J. F., Huang, J. F., and Lloyd, S. J. (1994). Genetic identification of an autoinhibitor in CDPK, a protein kinase with a calmodulin-like domain. Biochemistry 33, 7267-7277.

Harper, J. F., Sussman, M. R., Schaller, G. E., Putnam-Evans, C., Charbonneau, H., and Harmon, A. C. (1991). A calcium-dependent protein kinase with a regulatory domain similar to calmodulin. Science 252, 951-954.

Hayashi, T., Banba, M., Shimoda, Y., Kouchi, H., Hayashi, M., and Imaizumi-Anraku, H. (2010). A dominant function of CCaMK in intracellular accommodation of bacterial and fungal endosymbionts. Plant $J$. 63, 141-154.

Heazlewood, J. L., Durek, P., Hummel, J., Selbig, J., Weckwerth, W., Walther, D., and Schulze, W. X. (2008). PhosPhAt: a database of phosphorylation sites in Arabidopsis thaliana and a plant-specific phosphorylation site predictor. Nucleic Acids Res. 36, D1015-D1021.

Hernandez Sebastia, C., Hardin, S. C., Clouse, S. D., Kieber, J. J., and Huber, S. C. (2004). Identification of a new motif for CDPK phosphorylation in vitro that suggests ACC synthase may be a CDPK substrate. Arch. Biochem. Biophys. 428, 81-91.

Hey, S. J., Byrne, E., and Halford, N. G. (2010). The interface between metabolic and stress signalling. Ann. Bot. 105, 197-203.

Hrabak, E. M., Chan, C. W., Gribskov, M., Harper, J. F., Choi, J. H., Halford, N., Kudla, J., Luan, S., Nimmo, H. G., Sussman, M. R., Thomas, M., WalkerSimmons, K., Zhu, J. K., and Harmon, A. C. (2003). The Arabidopsis CDPKSnRK superfamily of protein kinases. Plant Physiol. 132, 666-680.

Huang, J. Z., and Huber, S. C. (2001). Phosphorylation of synthetic peptides by a CDPK and plant SNF1-related protein kinase. Influence of proline and basic amino acid residues at selected positions. Plant Cell Physiol. 42, 1079-1087.

Huang, Y., Houston, N. L., Tovar-Mendez, A., Stevenson, S. E., Miernyk, J. A., Randall, D. D., and Thelen, J. J. (2010). A quantitative mass spectrometry-based approach for identifying protein kinase clients and quantifying kinase activity. Anal. Biochem. 402, 69-76

Ishida, S., Yuasa, T., Nakata, M., and Takahashi, Y. (2008). A tobacco calcium-dependent protein kinase, CDPK1, regulates the transcription factor REPRESSION OF SHOOT GROWTH in response to gibberellins. Plant Cell 20, 3273-3288. 
Ito, T., Nakata, M., Fukazawa, J., Ishida, S., and Takahashi, Y. (2010). Alteration of substrate specificity: the variable N-terminal domain of tobacco $\mathrm{Ca}(2+)$-dependent protein kinase is important for substrate recognition. Plant Cell 22, 1592-1604.

Ivashuta, S., Liu, J., Lohar, D. P., Haridas, S., Bucciarelli, B., Vandenbosch, K. A., Vance, C. P., Harrison, M. J., and Gantt, J. S. (2005). RNA interference identifies a calcium-dependent protein kinase involved in Medicago truncatula root development. Plant Cell 17, 2911-2921.

Jeong, J. C., Shin, D., Lee, J., Kang, C. H., Baek, D., Cho, M. J., Kim, M. C., and Yun, D. J. (2007). Isolation and characterization of a novel calcium/ calmodulin-dependent protein kinase, AtCK, from arabidopsis. Mol. Cells 24 , 276-282.

Johnson, C., Crowther, S., Stafford, M. J., Campbell, D. G., Toth, R., and Mackintosh, C. (2010). Bioinformatic and experimental survey of 14-3-3-binding sites. Biochem. J. 427, 69-78.

Kanchiswamy, C. N., Takahashi, H., Quadro, S., Maffei, M. E., Bossi, S., Bertea, C., Zebelo, S. A., Muroi, A., Ishihama, N., Yoshioka, H., Boland, W., Takabayashi, J., Endo, Y., Sawasaki, T., and Arimura, G. (2010). Regulation of Arabidopsis defense responses against Spodoptera littoralis by CPK-mediated calcium signaling. BMC Plant Biol. 10, 97. doi: 10.1186/1471-2229-10-97

Kato, N., Sakata, T., Breton, G., Le Roch, K. G., Nagle, A., Andersen, C., Bursulaya, B., Henson, K., Johnson, J., Kumar, K. A., Marr, F., Mason, D., Mcnamara, C., Plouffe, D., Ramachandran, V., Spooner, M., Tuntland, T., Zhou, Y., Peters, E. C., Chatterjee, A., Schultz, P. G., Ward, G. E., Gray, N., Harper, J., and Winzeler, E. A. (2008). Gene expression signatures and smallmolecule compounds link a protein kinase to Plasmodium falciparum motility. Nat. Chem. Biol. 4, 347-356.

Kersten, B., Agrawal, G. K., Durek, P., Neigenfind, J., Schulze, W., Walther, D., and Rakwal, R. (2009). Plant phosphoproteomics: an update. Proteomics 9, 964-988.

Kim, M. C., Chung, W. S., Yun, D. J., and Cho, M. J. (2009). Calcium and calmodulin-mediated regulation of gene expression in plants. Mol. Plant 2, 13-21.

Klimecka, M., and Muszynska, G. (2007). Structure and functions of plant calcium-dependent protein kinases. Acta Biochim. Pol. 54, 219-233.

Kobayashi, M., Ohura, I., Kawakita, K., Yokota, N., Fujiwara, M., Shimamoto, K., Doke, N., and Yoshioka, H. (2007). Calcium-dependent protein kinases regulate the production of reactive oxygen species by potato NADPH oxidase. Plant Cell 19, 1065-1080.

Kosuta, S., Hazledine, S., Sun, J., Miwa, H., Morris, R. J., Downie, J. A., and Oldroyd, G. E. (2008). Differential and chaotic calcium signatures in the symbiosis signaling pathway of legumes. Proc. Natl. Acad. Sci. U.S.A. 105, 9823-9828.

Kyono, Y., Sugiyama, N., Tomita, M., and Ishihama, Y. (2010). Chemical dephosphorylation for identification of multiply phosphorylated peptides and phosphorylation site determination. Rapid Commun. Mass Spectrom. 24, 2277-2282.

Lambeck, I., Chi, J. C., Krizowski, S., Mueller, S., Mehlmer, N., Teige, M., Fischer, K., and Schwarz, G. (2010). Kinetic analysis of 14-3-3-inhibited Arabidopsis thaliana nitrate reductase. Biochemistry 49, 8177-8186.

Lecourieux, D., Ranjeva, R., and Pugin, A. (2006). Calcium in plant defencesignalling pathways. New Phytol. 171, 249-269.

Liu, F., Yoo, B. C., Lee, J. Y., Pan, W., and Harmon, A. C. (2006). Calciumregulated phosphorylation of soybean serine acetyltransferase in response to oxidative stress. J. Biol. Chem. 281, 27405-27415.

Lourido, S., Shuman, J., Zhang, C., Shokat, K. M., Hui, R., and Sibley, L. D. (2010). Calcium-dependent protein kinase 1 is an essential regulator of exocytosis in Toxoplasma. Nature 465, 359-362.

Luan, S., Lan, W., and Chul Lee, S. (2009). Potassium nutrition, sodium toxicity, and calcium signaling: connections through the CBL-CIPK network. Curr Opin. Plant Biol. 12, 339-346.

Ludwig, A. A., Saitoh, H., Felix, G. Freymark, G., Miersch, O., Wasternack, C., Boller, T., Jones, J. D., and Romeis, T. (2005). Ethylene-mediated cross-talk between calcium-dependent protein kinase and MAPK signaling controls stress responses in plants. Proc. Natl. Acad. Sci. U.S.A. 102, 10736-10741.

Ma, S. Y., and Wu, W. H. (2007). AtCPK23 functions in Arabidopsis responses to drought and salt stresses. Plant Mol. Biol. 65, 511-518.

Ma, W., and Berkowitz, G. A. (2007). The grateful dead: calcium and cell death in plant innate immunity. Cell. Microbiol. 9, 2571-2585.

Marsh, J. F., Rakocevic, A., Mitra, R. M., Brocard, L., Sun, J., Eschstruth, A., Long, S. R., Schultze, M., Ratet, P., and Oldroyd, G. E. (2007). Medicago truncatula NIN is essential for rhizobial-independent nodule organogenesis induced by autoactive calcium/ calmodulin-dependent protein kinase. Plant Physiol. 144, 324-335.
Mazars, C., Bourque, S., Mithofer, A., Pugin, A., and Ranjeva, R. (2009). Calcium homeostasis in plant cell nuclei. New Phytol. 181, 261-274.

McAinsh, M. R., and Pittman, J. K. (2009). Shaping the calcium signature. New Phytol. 181, 275-294.

McCubbin, A. G., Ritchie, S. M., Swanson, S. J., and Gilroy, S. (2004). The calcium-dependent protein kinase HvCDPK1 mediates the gibberellic acid response of the barley aleurone through regulation of vacuolar function. Plant J. 39, 206-218.

Mehlmer, N., Wurzinger, B., Stael, S., Hofmann-Rodrigues, D., Csaszar, E., Pfister, B., Bayer, R., and Teige, M. (2010). The $\mathrm{Ca}(2+)$-dependent protein kinase $\mathrm{CPK} 3$ is required for MAPK-independent salt-stress acclimation in Arabidopsis. Plant J. 63 , 484-498.

Milla, M. A., Townsend, J., Chang, I. F., and Cushman,J.C. (2006). The Arabidopsis AtDi19 gene family encodes a novel type of Cys2/His2 zinc-finger protein implicated in ABA-independent dehydration, high-salinity stress and light signaling pathways. Plant Mol. Biol. 61, 13-30.

Mori, I.C., Murata, Y., Yang, Y., Munemasa, S., Wang, Y. F., Andreoli, S., Tiriac, H. Alonso, J. M., Harper, J. F., Ecker, J. R., Kwak, J. M., and Schroeder, J. I. (2006). CDPKs CPK6 and CPK3 function in ABA regulation of guard cell S-type anion- and $\mathrm{Ca}(2+)$-permeable channels and stomatal closure. PLoS Biol. 4, e327. doi: 10.1371/journal. pbio.0040327

Munemasa, S., Hossain, M. A., Nakamura, Y., Mori, I. C., and Murata, Y. (2011). The Arabidopsis calcium-dependent protein kinase, CPK6, functions as a positive regulator of methyl jasmonate signaling in guard cells. Plant Physiol. $155,553-561$.

Myers, C., Romanowsky, S. M., Barron, Y. D., Garg, S., Azuse, C. L., Curran, A. Davis, R. M., Hatton, J., Harmon, A. C., and Harper, J. F. (2009). Calciumdependent protein kinases regulate polarized tip growth in pollen tubes. Plant J. 59, 528-539.

Nakagami, H., Sugiyama, N., Mochida, K., Daudi, A., Yoshida, Y., Toyoda, T. Tomita, M., Ishihama, Y., and Shirasu, K. (2010). Large-scale comparative phosphoproteomics identifies conserved phosphorylation sites in plants. Plant Physiol. 153, 1161-1174.

Nuhse, T. S., Bottrill, A. R., Jones, A. M., and Peck, S. C. (2007). Quantitative phosphoproteomic analysis of plasma membrane proteins reveals regulatory mechanisms of plant innate immune responses. Plant J. 51, 931-940.

Nuhse, T. S., Stensballe, A., Jensen, O. N. and Peck, S. C. (2003). Large-scale analysis of in vivo phosphorylated membrane proteins by immobilized metal ion affinity chromatography and mass spectrometry. Mol. Cell Proteomics 2, 1234-1243.

Nuhse, T. S., Stensballe, A., Jensen, O. N., and Peck, S. C. (2004). Phosphoproteomics of the Arabidopsis plasma membrane and a new phosphorylation site database. Plant Cell 16, 2394-2405.

Oldroyd, G. E., and Downie, J. A. (2006). Nuclear calcium changes at the core of symbiosis signalling. Curr. Opin. Plant Biol. 9, 351-357.

Peck, S. C. (2006). Analysis of protein phosphorylation: methods and strategies for studying kinases and substrates. Plant J. 45, 512-522.

Perkins, D. N., Pappin, D. J., Creasy, D. M., and Cottrell, J. S. (1999). Probabilitybased protein identification by searching sequence databases using mass spectrometry data. Electrophoresis 20, 3551-3567.

Que, S., Wang, Y., Chen, P., Tang, Y. R. Zhang,Z., and He,H. (2010). Evaluation of protein phosphorylation site predictors. Protein Pept. Lett. 17, 64-69.

Rodriguez Milla, M. A., Uno, Y., Chang, I. F., Townsend, J., Maher, E. A., Quilici, D., and Cushman, J.C. (2006). A novel yeast two-hybrid approach to identify CDPK substrates: characterization of the interaction between AtCPK11 and AtDi19, a nuclear zinc finger protein. FEBS Lett. 580, 904-911.

Schroeder, M. J., Shabanowitz, J. Schwartz, J.C., Hunt, D. F., and Coon, J. J. (2004). A neutral loss activation method for improved phosphopeptide sequence analysis by quadrupole ion trap mass spectrometry. Anal. Chem. 76, 3590-3598.

Song, W.Y., Zhang, Z. B., Shao, H. B., Guo, X. L., Cao, H. X., Zhao, H. B., Fu, Z. Y., and $\mathrm{Hu}, \mathrm{X}$. J. (2008). Relationship between calcium decoding elements and plant abiotic-stress resistance. Int. J. Biol. Sci. 4, 116-125.

Sugiyama, N., Nakagami, H., Mochida, K., Daudi, A., Tomita, M., Shirasu, K., and Ishihama, Y. (2008). Largescale phosphorylation mapping reveals the extent of tyrosine phosphorylation in Arabidopsis. Mol. Syst. Biol. 4, 193.

Tirichine, L., Imaizumi-Anraku, H. Yoshida, S., Murakami, Y., Madsen, L. H., Miwa, H., Nakagawa, T., Sandal, N., Albrektsen, A. S., Kawaguchi, M. Downie, A., Sato, S., Tabata, S., Kouchi, H., Parniske, M., Kawasaki, S., and Stougaard, J. (2006). Deregulation of a Ca2+/calmodulin-dependent kinase leads to spontaneous nodule development. Nature 441, 1153-1156.

Tsai, C. W., Chen, H. W., Yang, J. J., Sheen, L. Y., and Lii, C. K. (2007). 
Diallyl disulfide and diallyl trisulfide up-regulate the expression of the pi class of glutathione S-transferase via an AP-1-dependent pathway. J. Agric. Food Chem. 55, 1019-1026.

Uno, Y., Rodriguez Milla, M. A., Maher, E., and Cushman, J. C. (2009). Identification of proteins that interact with catalytically active calciumdependent protein kinases from Arabidopsis. Mol. Genet. Genomics 281, 375-390.

Vitart, V., Christodoulou, J., Huang, J. F., Chazin, W. J., and Harper, J. F. (2000a). Intramolecular activation of a $\mathrm{Ca}(2+)$-dependent protein kinase is disrupted by insertions in the tether that connects the calmodulin-like domain to the kinase. Biochemistry 39, 4004-4011.

Vitart, V. V., Christodoulou, J., Huang, J. F., Chazin, W. J., and Harper, J. F. (2000b). Intramolecular activation of a $\mathrm{Ca}(2+)$-dependent protein kinase is disrupted by insertions in the tether that connects the calmodulin-like domain to the kinase. Biochemistry 39, 12102.

Wernimont, A. K., Amani, M., Qiu, W., Pizarro, J.C., Artz, J. D., Lin, Y. H., Lew, J., Hutchinson, A., and Hui, R. (2011). Structures of parasitic CDPK domains point to a common mechanism of activation. Proteins 79, 803-820.

Wernimont,A. K., Artz, J. D., Finerty, P. Jr., Lin, Y. H., Amani, M., Allali-Hassani, A., Senisterra, G., Vedadi, M., Tempel, W., Mackenzie, F., Chau, I., Lourido, S., Sibley, L. D., and Hui, R. (2010). Structures of apicomplexan calciumdependent protein kinases reveal mechanism of activation by calcium. Nat. Struct. Mol. Biol. 17, 596-601.

Witte, C. P., Keinath, N., Dubiella, U., Demouliere, R., Seal, A., and Romeis, T. (2010). Tobacco calcium-dependent protein kinases are differentially phosphorylated in vivo as part of a kinase cascade that regulates stress response. J. Biol. Chem. 285, 9740-9748.

Xu, J., Tian, Y. S., Peng, R. H., Xiong, A. S., Zhu, B., Jin, X. F., Gao, F., Fu, X. Y., Hou, X. L., and Yao, Q. H. (2010). AtCPK6, a functionally redundant and positive regulator involved in salt/ drought stress tolerance in Arabidopsis. Planta 231, 1251-1260.

Yano, K., Yoshida, S., Muller, J., Singh, S., Banba, M., Vickers, K., Markmann, K., White, C., Schuller, B., Sato, S., Asamizu, E., Tabata, S., Murooka, Y., Perry, J., Wang, T. L., Kawaguchi, M., Imaizumi-Anraku, H., Hayashi, M., and Parniske, M. (2008). CYCLOPS, a mediator of symbiotic intracellular accommodation. Proc. Natl. Acad. Sci. U.S.A. 105, 20540-20545.

Yoon, G. M., Dowd, P. E., Gilroy, S., and Mccubbin, A. G. (2006). Calciumdependent protein kinase isoforms in Petunia have distinct functions in pollen tube growth, including regulating polarity. Plant Cell 18, 867-878.

Yuan, X., Deng, K. Q., Zhao, X. Y., Wu, X. J., Qin, Y.Z., Tang, D. Y., and Liu, X. M. (2007). A calcium-dependent protein kinase is involved in plant hormone signal transduction in Arabidopsis. Zhi Wu Sheng Li Yu Fen Zi Sheng Wu Xue Xue Bao 33, 227-234.

Zhu, S. Y., Yu, X. C., Wang, X. J., Zhao, R., Li, Y., Fan, R. C., Shang, Y., Du, S. Y., Wang, X. F., Wu, F. Q., Xu, Y. H., Zhang, X. Y., and Zhang, D. P. (2007). Two calcium-dependent protein kinases, CPK4 and CPK11, regulate abscisic acid signal transduction in Arabidopsis. Plant Cell 19, 3019-3036.

Zou, J. J., Wei, F. J., Wang, C., Wu, J. J., Ratnasekera, D., Liu, W. X., and Wu, W. H. (2010). Arabidopsis calciumdependent protein kinase CPK10 functions in abscisic acid- and Ca2+-mediated stomatal regulation in response to drought stress. Plant Physiol. 154, 1232-1243.
Conflict of Interest Statement: The authors declare that the research was conducted in the absence of any commercial or financial relationships that could be construed as a potential conflict of interest.

Received: 17 March 2011; accepted: 18 July 2011; published online: 30 August 2011.

Citation: Curran A, Chang I-F, Chang C-L, Garg S, Miguel RM, Barron YD, Li Y, Romanowsky S, Cushman JC, Gribskov M, Harmon AC and Harper JF (2011) Calcium-dependent protein kinases from Arabidopsis show substrate specificity differences in an analysis of 103 substrates. Front. Plant Sci. 2:36. doi: 10.3389/ fpls.2011.00036

This article was submitted to Frontiers in Plant Physiology, a specialty of Frontiers in Plant Science.

Copyright (c) 2011 Curran, Chang, Chang, Garg, Miguel, Barron, Li, Romanowsky, Cushman, Gribskov, Harmon and Harper. This is an open-access article subject to a non-exclusive license between the authors and Frontiers Media SA, which permits use, distribution and reproduction in other forums, provided the original authors and source are credited and other Frontiers conditions are complied with. 